\title{
Loss of SMAD4 Alters BMP Signaling to Promote Colorectal Cancer Cell Metastasis via Activation of Rho and ROCK
}

\author{
Philip W. Voorneveld, ${ }^{1, *}$ Liudmila L. Kodach, ${ }^{1, *}$ Rutger J. Jacobs, ${ }^{1}$ Nalan Liv, ${ }^{2}$ \\ A. Christiaan Zonnevylle, ${ }^{2}$ Jacob P. Hoogenboom, ${ }^{2}$ Izak Biemond, ${ }^{1}$ Hein W. Verspaget, ${ }^{1}$ \\ Daniel W. Hommes, ${ }^{1,3}$ Karien de Rooij, ${ }^{4,5}$ Carel J. M. van Noesel, ${ }^{6}$ Hans Morreau, ${ }^{7}$ \\ Tom van Wezel, ${ }^{7}$ G. Johan A. Offerhaus, ${ }^{8}$ Gijs R. van den Brink, ${ }^{9,10}$ \\ Maikel P. Peppelenbosch, ${ }^{11}$ Peter ten Dijke, ${ }^{12}$ and James C. H. Hardwick ${ }^{1}$
}

\begin{abstract}
${ }^{1}$ Department of Gastroenterology and Hepatology, ${ }^{4}$ Department of Radiology, ${ }^{7}$ Department of Pathology, ${ }^{12}$ Department of Molecular Cell Biology, Cancer Genomics Centre Netherlands and Centre for Biomedical Genetics, Leiden University Medical Center, Leiden, The Netherlands; ${ }^{2}$ Department of Imaging Science and Technology, Faculty of Applied Sciences, Delft University of Technology, Delft, The Netherlands; ${ }^{3}$ Center for Inflammatory Bowel Diseases, University of California Los Angeles Medical Center, Santa Monica, California; ${ }^{5}$ Percuros B.V., Leiden, The Netherlands; ${ }^{6}$ Department of Pathology, ${ }^{9}$ Department of Gastroenterology and Hepatology, ${ }^{10}$ Tytgat Institute for Liver and Intestinal Research, Academic Medical Center, Amsterdam, The Netherlands; ${ }^{8}$ Department of Pathology, University Medical Center, Utrecht, The Netherlands; ${ }^{11}$ Department of Gastroenterology and Hepatology, Erasmus MC, Erasmus University Rotterdam, Rotterdam, The Netherlands
\end{abstract}

\section{See Covering the Cover synopsis on page 2.}

BACKGROUND \& AIMS: SMAD4 frequently is lost from colorectal cancers (CRCs), which is associated with the development of metastases and a poor prognosis. SMAD4 loss is believed to alter transforming growth factor $\beta$ signaling to promote tumor progression. However, SMAD4 is also a central component of the bone morphogenetic protein (BMP) signaling pathway, implicated in CRC pathogenesis by human genetic studies. We investigated the effects of alterations in BMP signaling on the invasive and metastatic abilities of CRC cells and changes in members in this pathway in human tumor samples. METHODS: We activated BMP signaling in SMAD4positive and SMAD4-negative CRC cells (HCT116, HT-29, SW480, and LS174T); SMAD4 was stably expressed or knocked down using lentiviral vectors. We investigated the effects on markers of epithelial-mesenchymal transition and on cell migration, invasion, and formation of invadopodia. We performed kinase activity assays to characterize SMAD4independent BMP signaling and used an inhibitor screen to identify pathways that regulate CRC cell migration. We investigated the effects of the ROCK inhibitor Y-27632 in immunocompromised (CD-1 Nu) mice with orthotopic metastatic tumors. Immunohistochemistry was used to detect BMPR1a, BMPR1b, BMPR2, and SMAD4 in human colorectal tumors; these were related to patient survival times. RESULTS: Activation of BMP signaling in SMAD4-negative cells altered protein and messenger RNA levels of markers of epithelial-mesenchymal transition and increased cell migration, invasion, and formation of invadopodia. Knockdown of the BMP receptor in SMAD4-negative cells reduced their invasive activity in vitro. SMAD4-independent BMP signaling activated Rho signaling via ROCK and LIM domain kinase (LIMK). Pharmacologic inhibition of ROCK reduced metastasis of colorectal xenograft tumors in mice. Loss of SMAD4 from colorectal tumors has been associated with reduced survival time; we found that this association is dependent on the expression of BMP receptors but not transforming growth factor $\beta$ receptors. CONCLUSIONS: Loss of SMAD4 from colorectal cancer cells causes BMP signaling to switch from tumor suppressive to metastasis promoting. Concurrent loss of SMAD4 and normal expression of BMP receptors in colorectal tumors was associated with reduced survival times of patients. Reagents that interfere with SMAD4-independent BMP signaling, such as ROCK inhibitors, might be developed as therapeutics for CRC.

Keywords: Colon Cancer; Signal Transduction; Transcription; Tumor Progression.

Colorectal cancer (CRC) remains a frequently fatal disease because of the high incidence of metastases for which current therapy is largely unsuccessful. This makes the understanding of the process of metastasis critical to improve the prognosis.

Loss of SMAD4 is seen in $30 \%-40 \%$ of CRCs, ${ }^{1}$ occurs late in the adenoma-to-carcinoma sequence, ${ }^{2}$ and is associated with liver metastases, a poor prognosis, and a poor response to chemotherapy. ${ }^{3,4}$ SMAD4 is the central critical signal transduction element of the transforming growth factor (TGF)- $\beta$ signaling pathway. The consequences of loss of SMAD4 therefore initially were ascribed to the loss of canonical TGF $\beta$ signaling. However, in many cancers, $\operatorname{TGF} \beta$

*Authors share co-first authorship.

Abbreviations used in this paper: BMP, bone morphogenetic protein; BMPR, bone morphogenetic protein receptor; CRC, colorectal cancer; EMT, epithelial-mesenchymal transition; GSK, glycogen synthase kinase; mRNA, messenger RNA; PBS, phosphate-buffered saline; TGF, transforming growth factor; TGF $\beta$ R1, transforming growth factor $\beta$ receptor 1 .

(C) 2014 by the AGA Institute $0016-5085 / \$ 36.00$

http://dx.doi.org/10.1053/j.gastro.2014.03.052 
switches from being a tumor suppressor to become a tumor promoter, driving invasion and metastasis. ${ }^{5}$

The nature of the switch that determines whether $\mathrm{TGF} \beta$ acts as a tumor suppressor or as a tumor promoter has been the subject of intense research. ${ }^{6,7}$ Mutant p53 has been shown to be one potential explanation, ${ }^{8}$ however, another study has shown that SMAD4 mutations bring about this switch. ${ }^{9}$

To date, most research into the role of SMAD4 in CRC has focused exclusively on its role as part of the $\operatorname{TGF} \beta$ pathway. However, SMAD4 is also the central component of the bone morphogenetic protein (BMP) signaling pathway that we and others have shown plays an important role in cancer development. ${ }^{1,10,11}$ There is even perhaps stronger evidence for a critical role for the BMP pathway than for the $\mathrm{TGF} \beta$ pathway in CRC with germline mutations in BMP receptor 1A (BMPR1A) in juvenile polyposis but not in $\mathrm{TGF} \beta$ receptors, ${ }^{12}$ and from genome-wide association studies in CRC multiple associations exclusively within the BMP pathway (BMP2, BMP4, BMPR1A, and Gremlin1) but none exclusively within the TGF $\beta$ pathway, whereas 2 others are involved in both (SMAD4 and SMAD7). ${ }^{13,14}$ BMP signaling classically is regarded as tumor suppressive in CRC, inducing cell differentiation and apoptosis of colonic epithelial cells and negatively regulating Wnt signaling. ${ }^{10,15}$ However, although some studies have shown that activation of BMP signaling results in growth suppression and induction of differentiation in cancer cell lines, ${ }^{10,16}$ others have found that BMP activation leads to prometastatic effects. ${ }^{17}$

In this study, we set out to investigate the role of BMP signaling in the processes of epithelial-mesenchymal transition (EMT), invasion, and metastasis in CRC with particular focus on the role of loss of SMAD4 and SMAD4independent signaling (also known as noncanonical or non-SMAD BMP signaling).

\section{Materials and Methods}

\section{Invasion Assay}

Cells were labeled with $5 \mu \mathrm{mol} / \mathrm{L}$ CellTracker Green 5-chloromethylfluorescein diacetate (CMFDA) (Invitrogen, Breda, The Netherlands) after which they were detached using trypsin with 2 $\mathrm{mmol} / \mathrm{L}$ ethylenediaminetetraacetic acid (EDTA). A total of $10^{5}$ cells/insert were transferred to $8-\mu \mathrm{mol} / \mathrm{L}$ pore size HTS FluoroBlok Cell Culture Inserts (BD Falcon, Breda, The Netherlands) in medium containing $1 \%$ fetal calf serum. The inserts were coated with $100 \mu \mathrm{L}$ of a 1:1 mix of serum-free medium and Matrigel (BD Biosciences, Breda, The Netherlands). Inserts were placed in 24well plates (Corning, Inc, Corning, NY) in which $600 \mu \mathrm{L}$ of $10 \%$ fetal calf serum-containing media without phenol red were present. Fluorescence of the invaded cells at the bottom well of the Transwell was measured every 2 hours using the BioTek Flx800 (BioTek, Winooski, VT). Data were corrected for background fluorescence and migration start points were set to zero.

\section{Liver Metastases Model}

Liver metastasis were generated by injecting $0.5 * 10^{6}$ HT29 cells expressing luciferase dissolved in $50 \mu \mathrm{L}$ of medium:Matrigel (1:1) into the spleens of 6-week-old immunocompromised CD1 nude mice (males). The spleen was not removed after injection. The mice were treated by intraperitoneal injection with $2.5 \mathrm{mg} / \mathrm{kg} \mathrm{Y}-27632$ (R\&D Systems, Abingdon, United Kingdom) dissolved in phosphate-buffered saline (PBS) $(\mathrm{n}=9)$ or with PBS ( $\mathrm{n}=9$ ) every other day. Weekly bioluminescence scans were performed and after 7 weeks the mice were killed. The model is described in detail in the Supplementary Materials and Methods section.

\section{Simultaneous Correlative Scanning Electron and High Numeric Aperture Fluorescence Microscopy}

This new technique uses a combination of correlative scanning electron microscopy and high numeric aperture fluorescence microscopy. For a complete microscope set-up and explanation of tissue and staining methods we refer to 2 articles from Zonnevylle et $\mathrm{al}^{18}$ and Liv et $\mathrm{al}^{19}{ }^{19}$ and the Supplementary Materials and Methods section.

\section{Peptide Array}

Samples were analyzed using peptide arrays containing 960 fully annotated, disease-related kinase phosphorylation sites. Procedures for performing the peptide arrays have been described in detail elsewhere and can be found in the Supplementary Materials and Methods section.

\section{Tissue Microarray}

Immunohistochemistry for SMAD4, BMPR1A, BMPR1B, BMPR2, TGF $\beta$ receptor 1 (TGF $\beta$ R1), and TGF $\beta$ R2 was performed in colorectal cancer tissue of 145 patients included on a tissue microarray. Each individual tumor was represented by 3 separate $0.6-\mathrm{mm}$ cores on the tissue microarray as well as 1 core of normal colon mucosa. Patient information and immunohistochemistry protocols can be found in the Supplementary Materials and Methods section.

\section{Results}

\section{SMAD4 Loss Switches BMP Signaling From Tumor Suppressive to Prometastatic}

To investigate the effects of BMP signaling in the context of SMAD4 loss we used the isogenic CRC cell lines HCT116 and HCT116 SMAD4-/-. HCT116 cells are known to express low levels of BMPR2 and transfection of BMPR2 results in a major increase in SMAD4-dependent (canonical) BMP signaling activity measured using a BMP reporter element (BRE)-luciferase reporter construct (BRE-Luc) as we have shown previously. ${ }^{1}$ Transfection of BMPR2 in HCT116 SMAD4-/- cells does not lead to an increase in BREluciferase activity (Supplementary Figure $1 A$ and $B$ ). Activation of BMP signaling in SMAD4-/- cells using BMPR2 transfection results in a decrease in E-cadherin messenger RNA (mRNA) expression and an increase in vimentin and the transcription factors SNAI1, SLUG1, and ZEB1, suggesting induction of EMT (Figure $1 A$ ). In contrast, activation of BMP signaling in the SMAD4-expressing HCT116 cells does not result in EMT, but increases E-cadherin expression, suggesting a change toward a more epithelial-like state. $\mathrm{TGF} \beta \mathrm{R} 2$ transfection is used as a control because it is known 
to induce EMT. To confirm the changes seen at the mRNA level we checked for protein expression changes in E-cadherin and vimentin using immunoblot analysis and fluorescent immunocytochemistry and saw similar effects at the protein level as seen at the mRNA level (Figure $1 B$ and $C$ ). Inhibition of BMP signaling using the small-molecule BMPR1A inhibitor LDN-193189 in SMAD4-/- cells results in a change to more epithelial-like cells (Supplementary
A

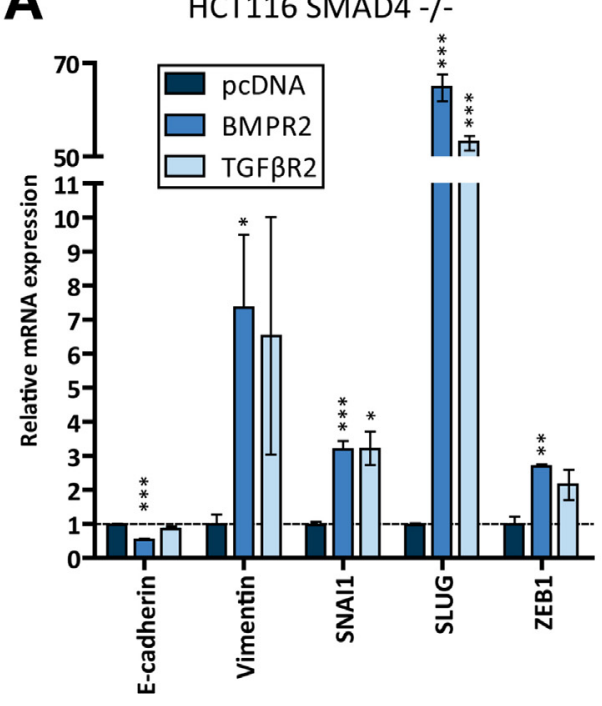

C

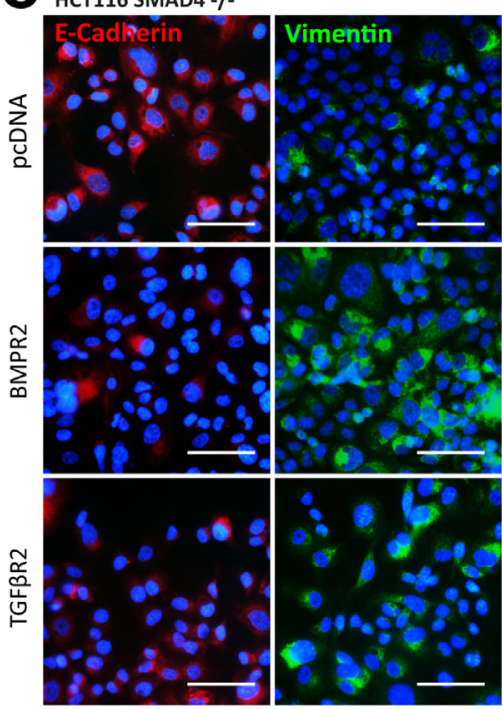

E

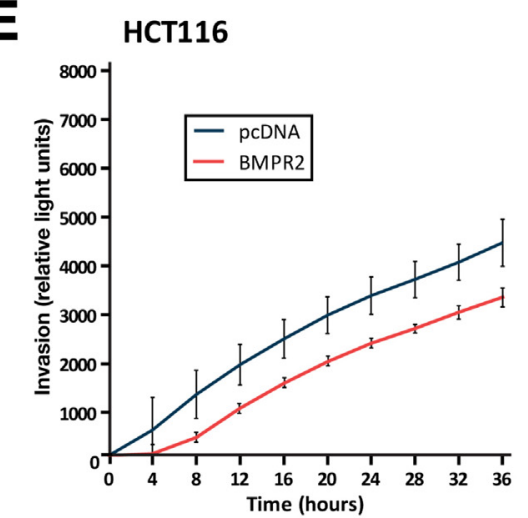

HCT116 SMAD4 +/+

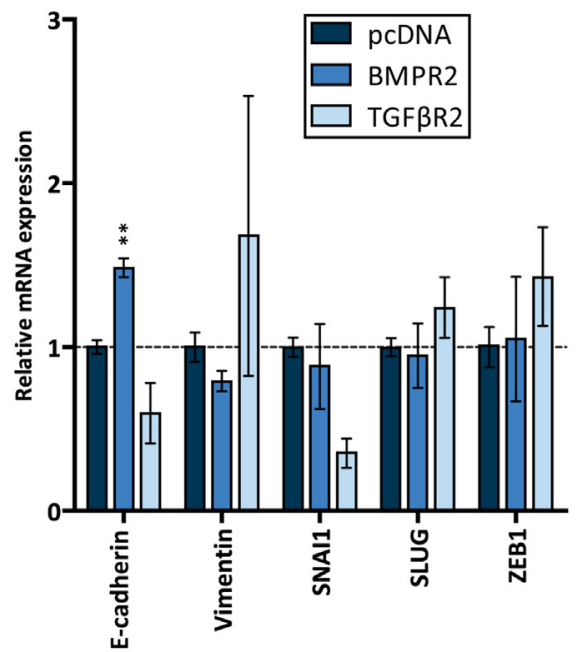

B

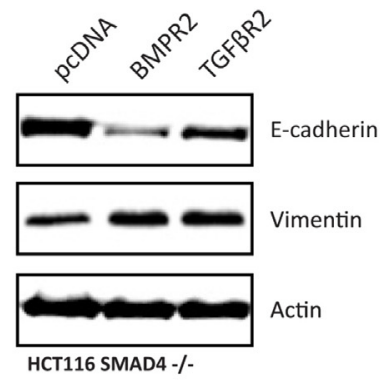

D

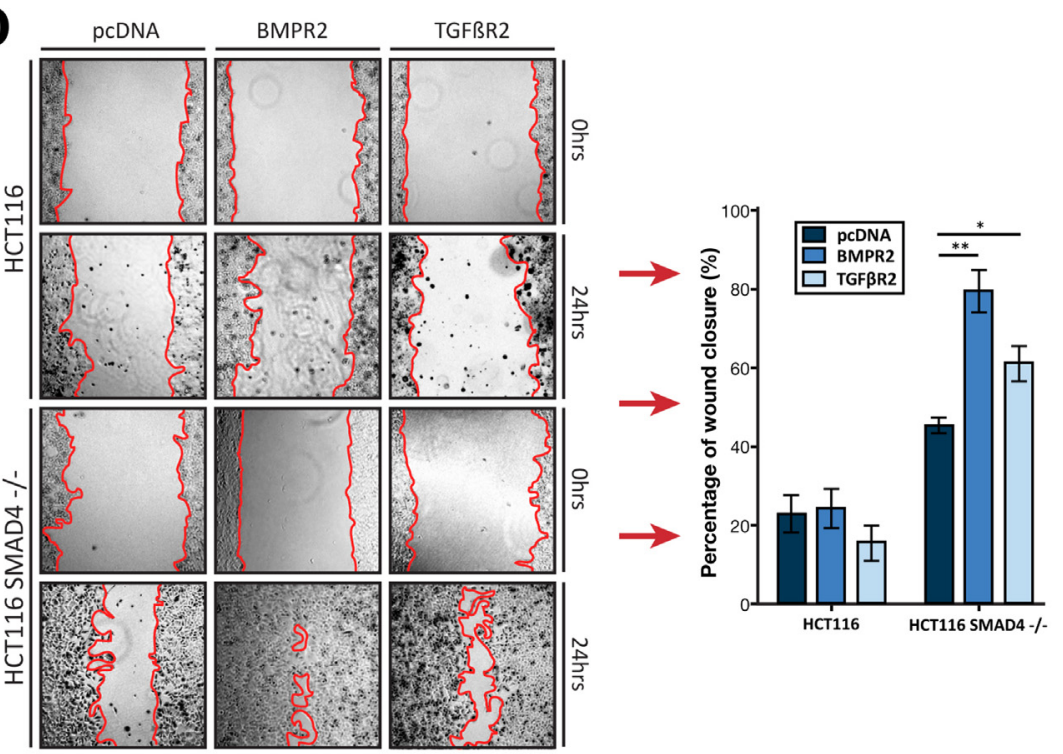

HCT116 SMAD4 -/-

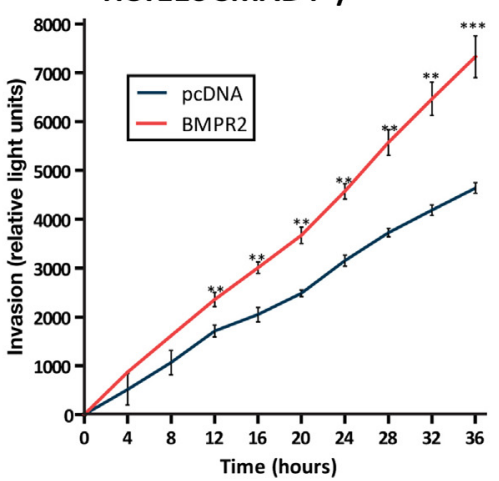

F

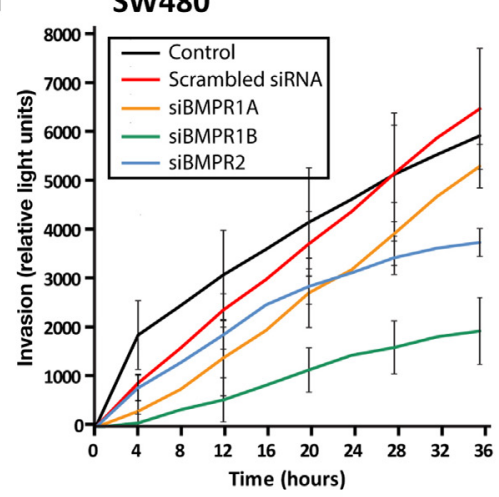


Figure $1 C$ ). We also reconstituted SMAD4 expression in SMAD4-negative CRC cells and observed a change into more epithelial-like cells based on E-cadherin and vimentin RNA expression (Supplementary Figure 1D).

To assess changes in the functional aspects of the cancer cells we used scratch wound healing and MatrigelTranswell invasion assays. After BMPR2 transfection an increase in migration and invasion can be seen in the HCT116 SMAD4-/- cells, but not in the SMAD4-positive cells (Figure $1 D$ and $E$ ). We also reduced BMP signaling by silencing individual BMP receptors in the SMAD4-negative cell line SW480 and measured invasion over 36 hours. SW480 cells, in contrast to HCT116 cells, express high levels of BMP receptors, making them more suitable for BMP receptor silencing experiments. ${ }^{1}$ Knockdown of BMP receptor expression results in a decrease in invasion (invasion assay is shown in Figure $1 F$, Supplementary Figure 1 shows Western blots of BMP-receptor knockdown). Knockdown of BMPR1B leads to the most pronounced decrease in invasion, followed by knockdown of BMPR2.

Critical experiments were repeated using different BMP activation methods and different SMAD4-negative cell lines to avoid cell-line-specific bias (Supplementary Figure $1 E-H$ ). Overall, these data suggest that BMP signaling switches to a prometastatic pathway upon SMAD4 loss.

\section{SMAD4-Independent BMP Signaling Changes Cell Shape and Increases Invadopodia}

Phase-contrast images of SMAD4-independent BMP activation showed changes in cell shape with an increase in small cell protrusions (data not shown). To analyze these protrusions we used a new technique in which scanning electron microscopy and wide-field immunofluorescence can be combined simultaneously. ${ }^{18,19}$ SMAD4-independent BMP signaling was activated by transfection of BMPR2 in HCT116 SMAD4-/- cells, which resulted in more spindle-like cells (Figure 2A) with polarized distribution of actin and cortactin. There was also an increase in the number and size of protrusions. To confirm this observation we used an established and recognized technique in which colocalization of actin and cortactin molecularly identifies the presence of invadopodia. ${ }^{20}$ We calculated the amount of cells with invadopodia in the BMPR2-transfected cells and compared this with the control. A higher percentage of cells with invadopodia were seen in the condition in which SMAD4-independent BMP signaling was activated (Figure $2 B$ and $C$ ). A separate analysis of cell shape changes showed that BMP activation in the SMAD4-/- cells resulted in more spindle-shaped cell morphology typical of mesenchymal cells (Supplementary Figure 2).

\section{Comprehensive Analysis of the SMAD4- Independent BMP Signaling Cascade Using Kinome Profiling}

To assess the kinase activity changes associated with SMAD4-independent BMP signaling, HCT116 SMAD4-/- cells were transfected with BMPR2 or the empty pcDNA vector and subsequently a PepChip (Pepscan, Lelystad, The Netherlands) array was performed ${ }^{21,22}$ (Supplementary Figure 3). The most prominent effects seen in the peptide arrays were activation of signaling pathways responsible for cell migration, cell survival, and proliferation (Figure $3 A$ ). To establish the validity of the kinome profiling data the most consistent kinase activity changes were confirmed by immunoblotting with activation-specific antibodies against pAKT, p-glycogen synthase kinase $\alpha / \beta$, pp38MAPK, pMKK3/ 6, pJNK, pERK, p-LIMK, and SIP1 (Figure 3B).

We also activated noncanonical SMAD4-independent TGF $\beta$ signaling by transfecting TGF $\beta$ R2 into HCT116 SMAD4-/- cells. Our result show that SMAD4-independent BMP signaling is similar to SMAD4-independent TGF $\beta$ signaling, although the activation and phosphorylation of AKT is more prominent in cells transfected with TGF $\beta$ R2 than with BMPR2. Both signaling pathways are comparable in activating the Wnt pathway, but SMAD4-independent BMP signaling has more effect on the expression of SIP1/ ZEB2, a member of the $\delta E F-1$ family of 2-handed zinc finger nuclear factors associated with EMT.

\section{SMAD4-Independent BMP Signaling Induces EMT and Invasion via the ROCK Pathway}

Having established that SMAD4-independent BMP signaling induces EMT, migration, and invasion, and having identified the downstream signaling pathways involved, we set out to screen for which of these pathways primarily is responsible for the induction of EMT. We induced

Figure 1.SMAD4-independent BMP signaling induces EMT, migration, and invasion. (A) Activation of BMP and TGF $\beta$ signaling in HCT116 SMAD4-/- and HCT116 cells using BMPR2 and TGF $\beta$ R2 transient transfection. Quantitative polymerase chain reaction results, corrected for glyceraldehyde-3-phosphate dehydrogenase expression, are presented and pcDNA control values are set to 1. (B) Immunoblot analysis of E-cadherin and vimentin protein expression. Actin is used as a loading control. (C) Immunofluorescence staining of E-cadherin and vimentin protein expression. 4',6-diamidino-2-phenylindole is used to visualize cell nuclei. Scale bars: $50 \mu \mathrm{m}$. (D) Wound healing assay showing the wound healing after 24 hours. HCT116 and HCT116 SMAD4-/- cells were transfected transiently with pcDNA, BMPR2, or TGF $\beta$ R2 and a scratch was made in confluent cells. $(E)$ Invasion of HCT116 and HCT116 SMAD4-/- cells measured over a 36-hour time period in a MatrigelTranswell system. Cells were transfected transiently with pcDNA or BMPR2, labeled with the fluorescence label Cell tracker, and seeded in the upper chamber of a Transwell system. $(F)$ Invasion of SW480 cells transfected with either small interfering RNA against BMPR1A, BMPR1B, BMPR2, or scrambled small interfering RNA. Scrambled small interfering RNA was used as a control. Nontransfected SW480 cells were used as an additional control. Student $t$ tests were performed using the corrected means of the individual experiments $\left({ }^{*}<.05,{ }^{\star \star}<.001,{ }^{\star \star *}<.001\right)$. Data are presented as means \pm SEM. 

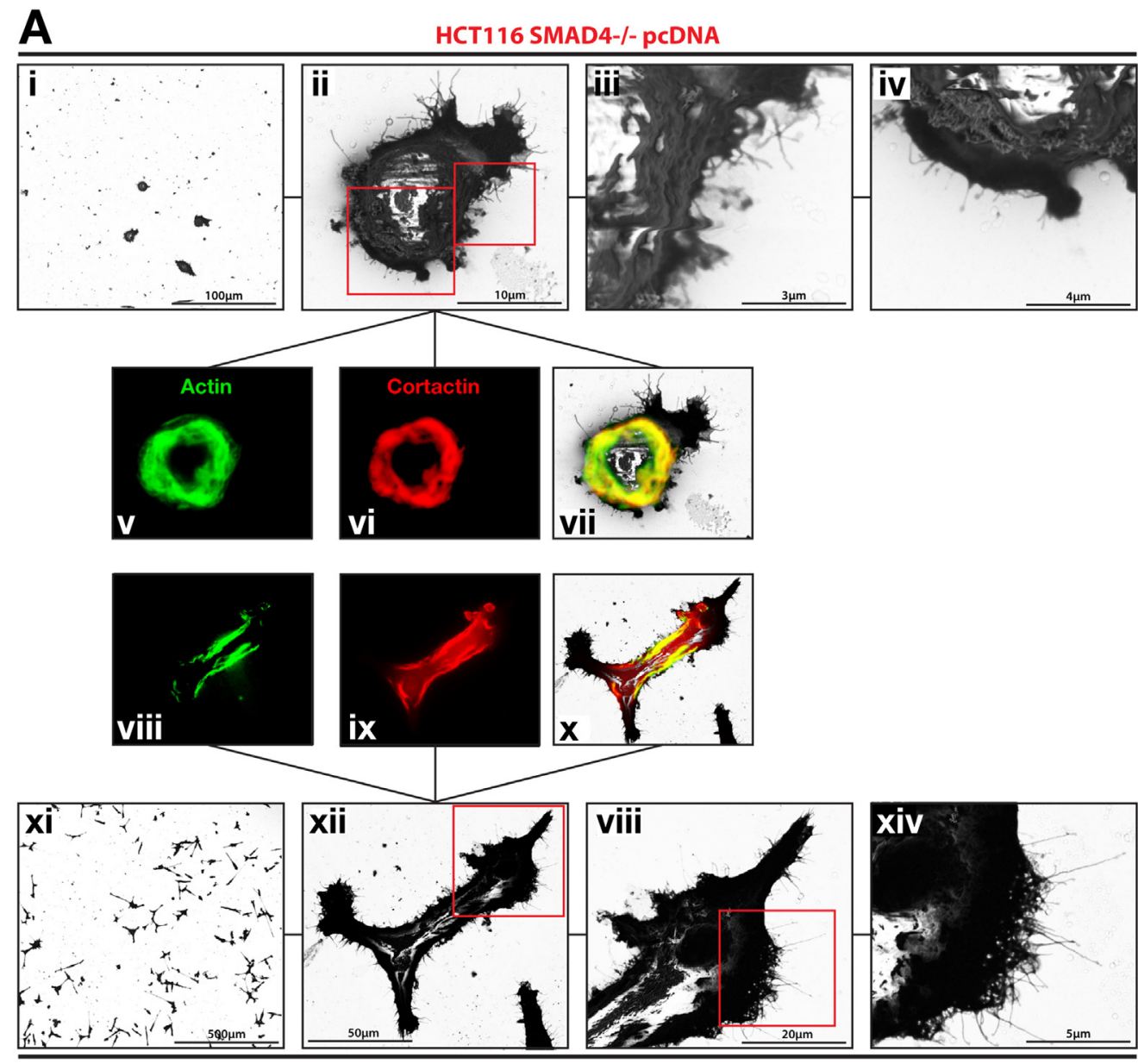

HCT116 SMAD4-/- BMPR2
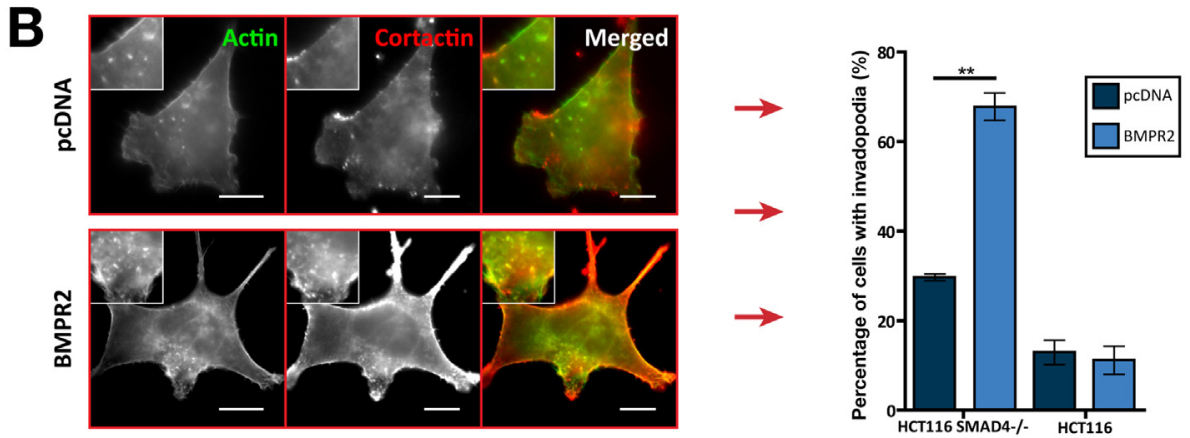

HCT116 SMAD4-I-

Figure 2. SMAD4-independent BMP signaling increases invadopodia formation. $(A)$ HCT116 SMAD4-/- cells were grown on ITO slides coated with poly-L-lysin and gelatin. Cells were transfected transiently with either pcDNA or BMPR2. After 24 hours the cells were fixed and stained for cortactin (mouse-anticortactin and anti-mouse AlexaFluor $594 \mathrm{~nm}$ ) and actin (phalloidin, $488 \mathrm{~nm}$ ). The indium-tin-oxide slides were placed in a simultaneous correlative scanning electron and high numeric aperture fluorescence microscope. Figures 1-7 are pcDNA samples. Figures 8-14 are BMPR2 samples. Figures 1-4 and 11-14 show that BMPR2-transfected cells show more cell protrusions. Figures 5-10 show the change in cell shape and actin/cortactin distribution after BMPR2 transfection. $(B)$ Phalloidin 488 was used to stain for actin and mouse-anticortactin plus anti-mouse AlexaFluor 594 for visualization for cortactin. Before staining, HCT116 and HCT116 SMAD4-/-cells were transfected transiently with either pcDNA or BMPR2. Scale bar: $5 \mu \mathrm{mol} / \mathrm{L}$. This figure only shows the HCT116 SMAD4-/- cells. Quantification of the experiment presented in panel $B$. Cells with co-localization of cortactin and actin were counted as having invadopodia. A cell showing 1 or more invadopodium was counted as positive. One hundred cells per condition were analyzed. The Student $t$ test was performed using the means of the individual experiments $\left({ }^{*}<.05,{ }^{\star \star}<.01,{ }^{* \star}<.001\right)$. Data are presented as means \pm SEM. 
SMAD4-independent BMP signaling using BMPR2 transfection in SMAD4-negative cells, treated the cells with a series of kinase inhibitors, and assessed vimentin expression by quantitative polymerase chain reaction (q-PCR). The use of pharmacologic inhibitors has the advantage that inhibitors can be tested further relatively easily as potential new CRC treatment options. Based on the reduction of vimentin expression (Figure $3 C$ ), the ROCK inhibitor Y-27632 is the most potent inhibitor of BMP-induced EMT.

\section{SMAD4-Independent BMP Signaling Activates the Rho/ROCK/LIMK Pathway}

Our next step was to investigate the connection between the BMP pathway and the ROCK pathway and to further evaluate the effects of ROCK inhibition.

First, we further assessed the role of SMAD4 in BMPinduced ROCK pathway activation. Activation of the BMP pathway in HCT116 SMAD4-/- cells lead to an increase in the phosphorylation of the Rho/ROCK downstream targets LIMK1/2 and cofilin (Figure 4A), but not in SMAD4-positive cells. Treatment with the ROCK inhibitor Y-27632 (2.5 $\mu \mathrm{mol} / \mathrm{L})$ lead to a decrease of phosphorylated ROCK downstream targets and an abolition of the effect of BMP pathway activation on the ROCK pathway in SMAD4-/- cells. Previous in vitro studies using Y-27632 have used various concentrations depending on the cell type $(1-20 \mu \mathrm{mol} / \mathrm{L}){ }^{23}$ In our experimental set-up, $2.5 \mu \mathrm{mol} / \mathrm{L}$ was the lowest concentration in which a major p-cofilin down-regulation could be seen (Supplementary Figure 4A). A direct connection between the BMP and ROCK pathways was investigated by transfecting cells with an HA-tagged BMPR2 construct, immunoprecipitating BMPR2 using anti-HA antibodies, and immunoblotting for LIMK (Figure $4 B$ ). This suggests a direct association between LIMK and BMPR2 in these cells.

Y-27632 abolishes the increase in wound healing, invasion, and invadopodia seen after the activation of SMAD4independent BMP signaling, showing that the effects of the BMP pathway on cell shape and migration/invasion are ROCK dependent (Figure $4 C-E$ ). We saw the same effects using different cell lines and both ligand and receptor-based BMP activation (Supplementary Figure $4 B-E$ ).

\section{The ROCK Inhibitor Y-27632 Reduces Metastases in an Orthotopic Liver Metastasis Model of SMAD4-Negative Colorectal Cancer}

To test the antimetastatic effects of ROCK inhibition we used a mouse model of liver metastasis in which fireflyluciferase-expressing human CRC cells are injected into the spleens of immunocompromised CD-1 Nu mice. The development of liver metastases was evaluated weekly using bioluminescence scans and after 7 weeks the mice were killed. We used the SMAD4-negative CRC cell line HT-29, which resulted more consistently in liver metastases in our hands than HCT116 and SW480. Activation of BMP signaling in HT29 also leads to the same increase in invasion without changes in cell viability in vitro comparable with other SMAD4-negative cell lines (Supplementary Figure 5A-C). Mice received either $2.5 \mathrm{mg} / \mathrm{kg}$ of Y-27632 dissolved in PBS or PBS intraperitoneally every other day. Eight of 9 of the control mice compared with 3 of 9 of the Y-27632-treated mice developed liver metastases (Figure 5A). There was a significant difference in total luminescence at week 7 between the control mice and the Y-27632-treated mice (Figure 5B). Quantification of the total whole-mouse scans is correlated closely with the quantification of ex vivo liver scans $\left(\mathrm{R}^{2}=0.95\right)$, showing that liver metastasis formation can be followed using in vivo whole-mouse scans in this model (Supplementary Figure 5D). Multiple random sections per liver were analyzed microscopically using H\&E. Metastases could be found in 8 of 9 of the control mice compared with 3 of 9 of the Y-27632-treated mice (Supplementary Figure 5G). Mice treated with Y-27632 had a significantly lower liver weight and volume (Supplementary Figure $5 E$ and $F$ ).

\section{SMAD4-Independent BMP Signaling Leads to a Poorer Prognosis}

Several studies consistently have shown that loss of SMAD4 expression in CRC is associated with a worse prognosis in patients. ${ }^{24,25}$ Our in vitro data suggest that this could be the result of SMAD4-independent BMP signaling. In a previous analysis of the expression of elements of the BMP pathway in CRC we observed frequent aberrant expression of the BMP receptors. ${ }^{1}$ We therefore would expect that concurrent loss of BMP-receptor expression would lead to a better prognosis in patients with SMAD4-negative cancers by reducing this SMAD4independent BMP signaling. In other words, the poor prognosis associated with loss of SMAD4 would be expected to be dependent on the presence of normal BMPreceptor expression in the tumor.

We mapped the expression patterns of SMAD4 and BMP receptors in patients using immunohistochemistry for SMAD4, BMPR1A, BMPR1B, and BMPR2 in a tissue microarray in 145 CRCs. Immunostaining was scored according to the system described in the Supplementary Materials and Methods section and cancers subsequently were ascribed to 1 of 4 categories based on the expression of SMAD4 and $\mathrm{BMP}$ receptors. Cancers were divided into SMAD4 positive and SMAD4 negative and these 2 groups then were subdivided into BMP-receptor positive and BMP-receptor negative. A patient was considered BMP-receptor negative if any 1 of the 3 BMP receptors had aberrant expression.

A total of $40.7 \%$ of the tumors had negative SMAD4 immunostaining, which is consistent with other studies (Supplementary Figure $6 A$ and $B$ ). Subdivision of the SMAD4-negative cancers into BMP-receptor positive and BMP-receptor deficient showed that the presence of normal BMP-receptor expression in the SMAD4-negative tumors is associated with a poor prognosis $(P=.005)$ (Figure $6 A$ ), suggesting that SMAD4-independent BMP signaling leads to a worse prognosis in patients. Conversely, patients with SMAD4-negative tumors with impaired BMP-receptor expression have a survival similar to those with normal SMAD4 expression. The poor prognosis found in cancers with SMAD4-independent BMP signaling is not independent 
A

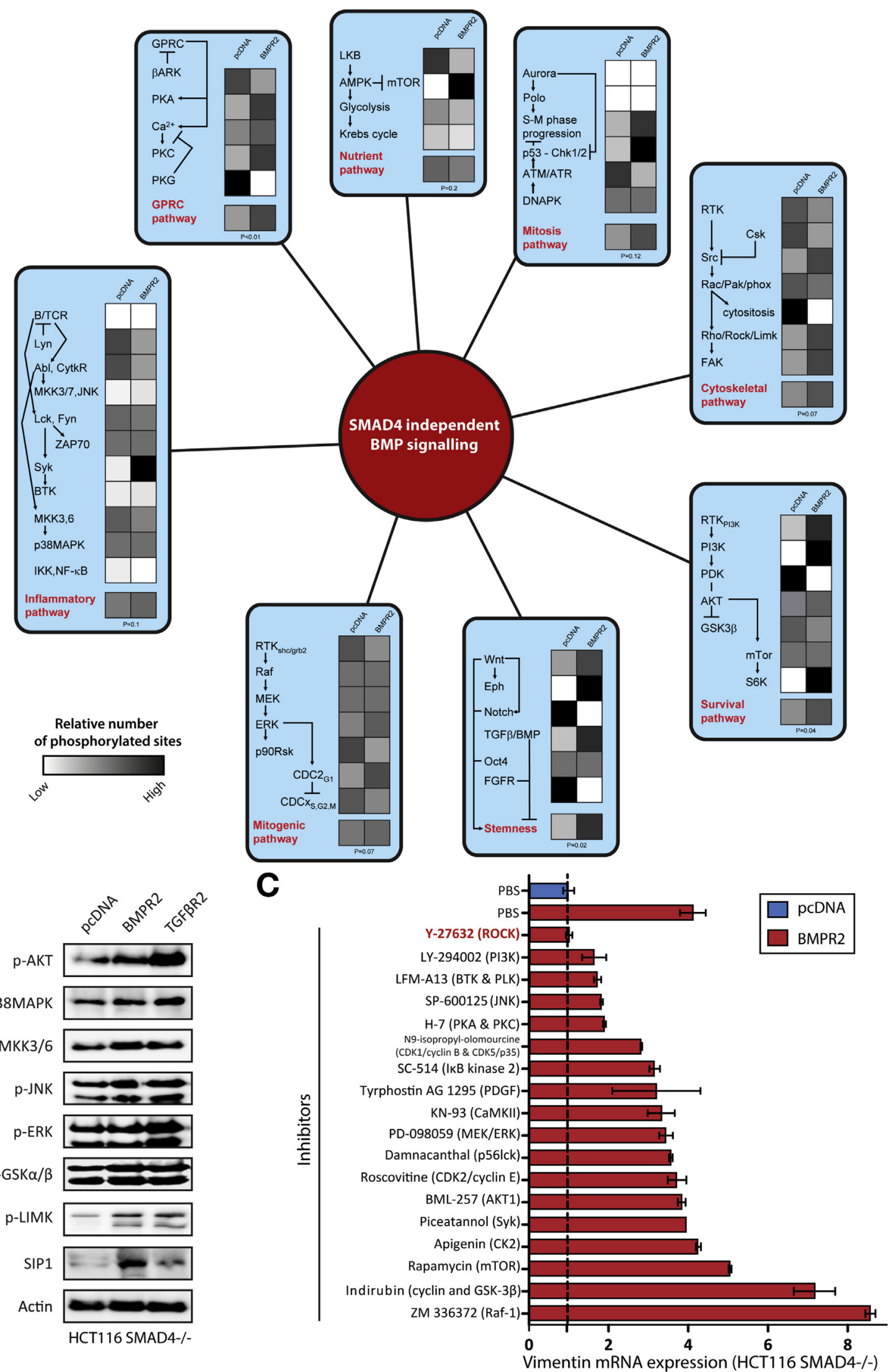


of tumor stage. This is probably because BMP-receptor expression in SMAD4-negative cancers is associated weakly with stage (Supplementary Figure 6C). Interestingly, there is no correlation between the poor prognosis seen in SMAD4-negative cancers and $\mathrm{TGF} \beta$-receptor expression $(P=.75)$ (Figure $6 C$, Supplementary Figure $6 C$ and $E$ show $\mathrm{TGF} \beta$-receptor expression frequencies and stage distribution). These findings are consistent with the conclusion that the poor prognosis seen in patients with SMAD4-negative cancers is owing to active SMAD4-independent BMP signaling rather than $\mathrm{TGF} \beta$ signaling.

\section{Discussion}

The data we present show that the BMP signaling pathway, which is a well-known tumor-suppressive pathway, changes into a prometastatic pathway upon loss of SMAD4. The current paradigm is that the poor survival associated with loss of SMAD4 is the result of effects on TGF $\beta$ signaling. We show that BMP signaling in the absence of SMAD4 leads to the activation of a broad range of signaling pathways and enhances invasion and metastasis.

BMP signaling has been associated previously with invasiveness. For example, BMP2 increases the motility and invasiveness of gastric cancer cell lines ${ }^{26}$ and BMP4 induces EMT in ovarian cancer cell lines, ${ }^{27}$ but the accepted view of BMP signaling is that of a tumor suppressor ${ }^{28}$ and a barrier to tumor progression and metastasis (reviewed by Wakefield and Hill $^{29}$ ). Here, we show that BMP signaling can be tumor promoting by increasing EMT and invasiveness in CRC and we show that this depends on the expression of SMAD4. A similar dual role has been seen with $\mathrm{TGF} \beta$, which initially is tumor suppressive but switches to tumor promoting in the later stages of cancer progression. ${ }^{30}$

The activation of SMAD4-independent BMP signaling also results in an increase in invadopodia. Invadopodia are transformed podosomes with the ability to degrade the extracellular matrix, ${ }^{31}$ allowing a transition to a more mesenchymal-like state. ${ }^{32}$ Identification of invadopodia can be performed by co-localization of cortactin and actin, ${ }^{20}$ which we used in our assay. We performed imaging in the same cells using a newly developed combined simultaneous correlative scanning electron microscope and a high numeric aperture fluorescence microscope that allowed us to visualize the distribution of actin and cortactin using fluorescent microscopy and the cell shape protrusions using scanning electron microscopy simultaneously. ${ }^{19}$ The fluorescent image does not show the typical spots of co-localized actin and cortactin seen at the tip of invadopodia with confocal microscopy because of the use of a wide-field fluorescent microscope that does not eliminate the light outside the focal plane. The combined fluorescent and electron microscope images do show an increase in cell protrusions and a change in the actin/cortactin distribution, implying a change in cell polarity associated with $\mathrm{EMT}^{33}$ after activation of SMAD4-independent BMP signaling.

Kinome profiling analysis showed that SMAD4independent BMP signaling activates a complex network of kinases. Among others, p38MAPK, ERK, JNK, PI3K, AKT, glycogen synthase kinase (GSK), and LIMK are activated targets of pathways involved in inflammation, mitosis, cell survival, proliferation, stemness, and cytoskeleton rearrangement.

The activation of p38MAPK, ERK, and JNK is consistent with previous reports of SMAD4-independent BMP7 signaling. ${ }^{34}$ Other changes have not been described before and include inhibition of GSK $\alpha / \beta$, which is part of the Axin/ adenomatous polyposis coli (APC)/GSK complex responsible for degrading $\beta$-catenin. Inhibiting GSK leads to an increase in $\beta$-catenin and thereby an increase in Wnt signaling activity. BMP signaling is known to oppose Wnt signaling,15 but not to enhance it as we observe here in SMAD4-negative cells. Although we show activation of AKT owing to activation of BMP signaling in SMAD4-negative cells, BMP signaling has been shown to inhibit proliferation via dephosphorylation of AKT in adrenocortical carcinomas. $^{35}$

The Rho/ROCK/LIMK pathway is involved in the reorganization of the cytoskeleton and in cell migration. BMP7 is known to activate the Rho/ROCK pathway in fibroblasts. ${ }^{36}$ It also is known to act downstream of BMP in neural development $^{37}$ and osteogenesis, ${ }^{38}$ but is not known to be a part of the BMP signaling cascade in epithelial cells. BMPR2 is known to interact directly with LIMK, ${ }^{39}$ which we confirmed in our experimental set-up. This may explain the connection between SMAD4-independent BMP signaling and the Rho/ROCK/LIMK pathway in CRC. We show that the Rho/ROCK/LIMK pathway is a critical component of the SMAD4-independent BMP signaling driving invasion and

Figure 3. Peptide array analysis of SMAD4-independent BMP signaling. (A) HCT116 SMAD4-/- cells were transfected transiently with either pcDNA or BMPR2. A PepChip peptide array was performed as described in the Supplementary Materials and Methods section. In the peptide array, phosphorylation changes in the substrates of 960 kinases were measured. The results were categorized according to well-known signaling pathways. A selection of the individual changes of specific targets within the pathway, as well as the changes in the whole pathway, is presented. For a full list of the kinome profiling changes see Supplementary Figure 4. (B) Validation of the results of kinome profiling using immunoblotting. (C) HCT116 SMAD4-/- cells were transfected transiently with either pcDNA or BMPR2. Subsequently, cells were treated with different kinase inhibitors from a commercial inhibitor screening kit. The median inhibitory concentration (found in the Supplementary Materials and Methods section) was used for each inhibitor. RNA was isolated and quantitative polymerase chain reaction was performed for vimentin expression. Glyceraldehyde-3-phosphate dehydrogenase was used as a control. The vimentin expression is presented as relative to the vimentin expression in the control condition. The Student $t$ test was performed using the corrected means of the individual experiments $\left({ }^{*}<.05,{ }^{* *}<.001,{ }^{* *}<.001\right)$. Data are presented as means \pm SEM. 
metastasis and represents a sensitive pharmacologic target by which to inhibit this. Clinically, ROCK is an interesting target for treatment because ROCK inhibitors, known by the name Fasudil, already have been used in patients. The use of Fasudil in patients with pulmonary hypertension and cerebral vasospasm did not lead to severe side effects. ${ }^{40,41}$ However, further safety assessment is imperative considering the fact that ROCK inhibition in mouse embryos resulted in developmental defects. ${ }^{42}$
Loss of SMAD4 protein expression is one of the best molecular prognostic markers in CRC. ${ }^{24}$ This is thought to be owing to loss of antimetastatic SMAD4-dependent TGF $\beta$ signaling. 9 However, when we subdivide patients with SMAD4-negative CRC into 2 groups according to the expression of BMP receptors, only the SMAD4-negative tumors that express high levels of BMP receptors have a poorer prognosis. Those with low BMP receptor expression have a prognosis similar to patients with SMAD4-positive CRC. In a
A
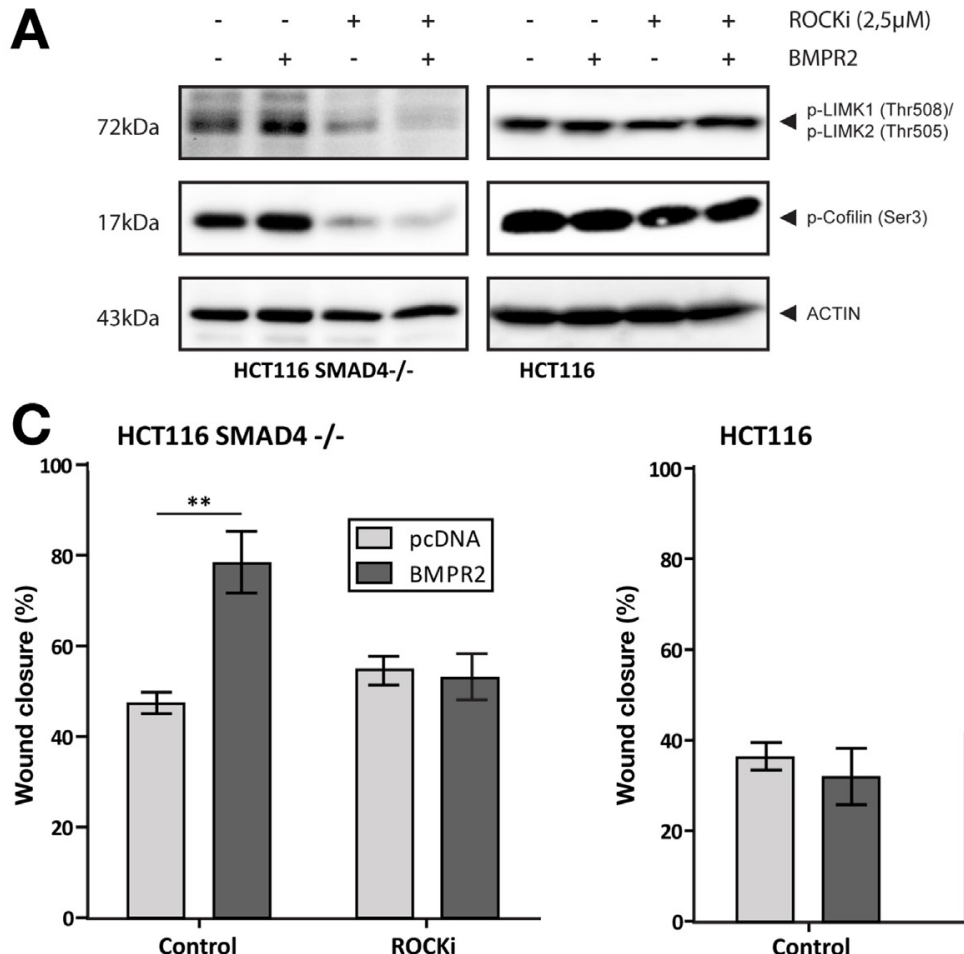

B

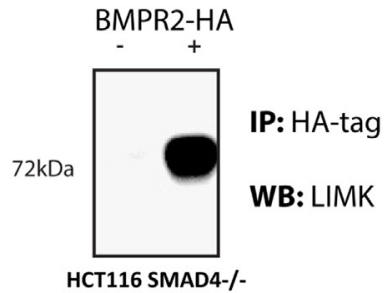

D HCT116 SMAD4 -/-

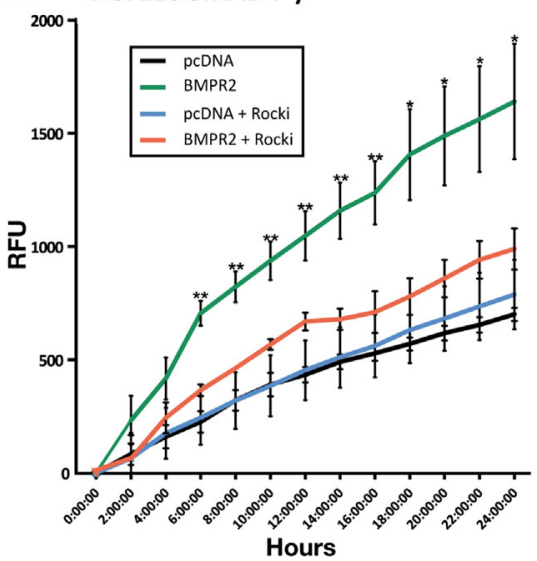

$\mathbf{E}$
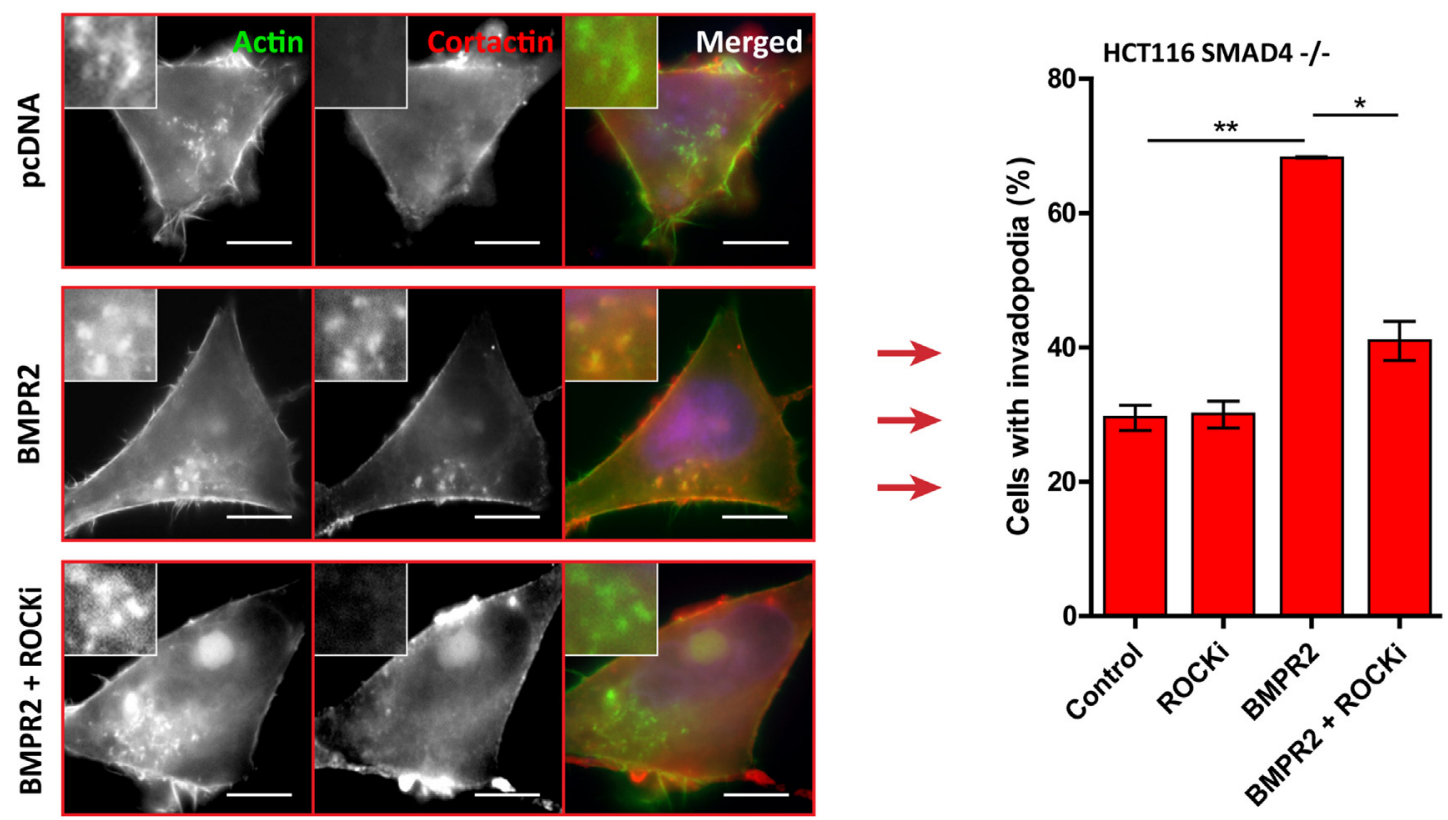
A

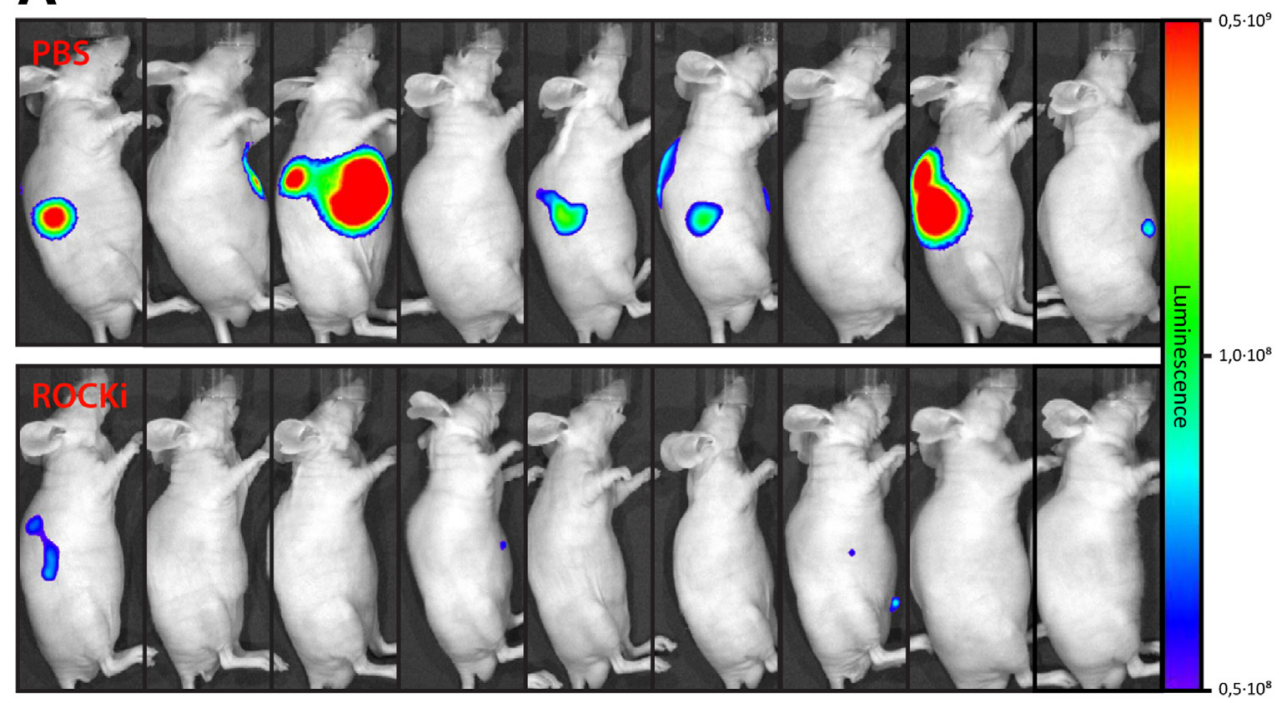

B

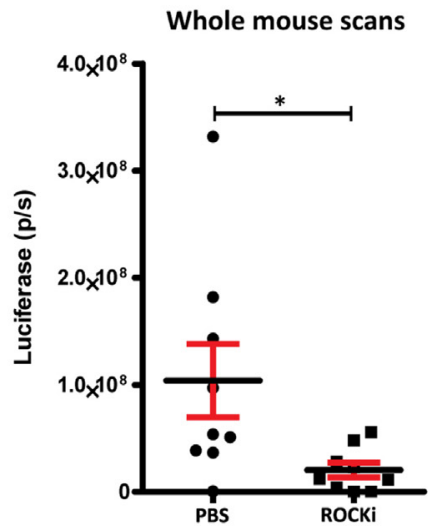

Figure 5. The ROCK inhibitor Y-27632 reduces colorectal cancer metastases in an orthotopic mouse model of liver metastasis. HT-29 cells $\left(10^{5}\right)$, which naturally express no SMAD4, stably transfected with an optimized firefly luciferase construct, were injected into spleens of CD-1 Nu mice suspended in $50 \mu \mathrm{L}$ of medium:Matrigel (50:50). Mice were treated with an intraperitoneal injection of either PBS $(n=9)$ or Rock inhibitor $(2.5 \mathrm{mg} / \mathrm{kg})(\mathrm{n}=9)$ every other day. Weekly bioluminescence scans were used to visualize liver metastasis formation. Seven weeks after the intrasplenic injection the mice were killed. (A) Bioluminescence whole-mouse scans at week 7. (B) Quantification of the whole-mouse scans at week 7. Comparison was made using the Student $t$ test.

similar analysis, TGF $\beta$-receptor expression shows no correlation with prognosis. BMPR and TGF $\beta$-receptor expression in SMAD4-negative CRC are both associated with more advanced stage, therefore, the association with prognosis is not independent of stage. Nevertheless, we believe this provides preliminary evidence in human beings that the BMP and not the TGF $\beta$ pathway is responsible for the poor prognosis associated with loss of SMAD4. It also suggests that SMAD4 is a good prognostic marker owing to its central role in the BMP pathway and not simply because it is a surrogate marker for aneuploidy as has been suggested. ${ }^{43}$ Furthermore, SMAD4 potentially can be refined as a prognostic marker by analysis of BMP-receptor expression.
To conclude, we have shown that upon SMAD4 loss, BMP signaling becomes prometastatic through activation of a broad program of SMAD4-independent BMP signaling. This consists of the activation of various downstream signaling pathways including the Rho/ROCK/LIMK pathway. Our patient data suggest that BMP signaling and not $\mathrm{TGF} \beta$ signaling is responsible for the poor prognosis associated with SMAD4 loss and that concurrent analysis of BMPR expression potentially can improve SMAD4 as a prognostic marker. These results would suggest that ROCK inhibitors might be a novel therapeutic approach in the subgroup of colorectal cancers that have lost SMAD4, a subgroup with a poor prognosis that respond poorly to current therapy.

Figure 4. SMAD4-independent BMP signaling activates the Rho/ROCK/LIMK pathway. $(A)$ Immunoblot analysis of HCT116 and HCT116 SMAD4-/- cells. Cells were transfected transiently with either BMPR2 or pcDNA vector. Subsequently, cells were treated with $2.5 \mu \mathrm{mol} / \mathrm{L}$ of ROCK inhibitor or PBS. Blots were incubated with antibodies against pLIMK1/2 and p-cofilin. Actin was used as a loading control. (B) HCT116 SMAD4-/- cells were transfected with BMPR2-HA (plasmid encoding both BMPR2 and $\mathrm{HA}$ tag). Cells were lysed and immunoprecipitation was performed using HA-tag antibodies and protein A agarose beads. Subsequently, Western blot analysis was performed and blots were exposed to LIMK antibodies. (C) Wound healing assay of HCT116 and HCT116 SMAD4-/- cells transiently transfected with either pcDNA or BMPR2 and treated with either $2.5 \mu$ mol/L ROCK inhibitor or PBS. After 24 hours, wound healing was quantified. (D) Invasion of HCT116 SMAD4-/- transfected with either pcDNA or BMPR2. Cells were labeled with Celltracker, seeded in the upper chamber of a Transwell system, and invasion was measured every 2 hours for 24 hours. $(E)$ Immunofluorescence pictures visualizing invadopodia by showing co-localization of actin and cortactin. Actin was visualized using phalloidin-488. Mouse-anticortactin plus anti-mouse AlexaFluor 594 was used to visualize cortactin. HCT116 SMAD4-/- cells were transfected transiently with either pcDNA or BMPR2. Subsequently, cells were treated with either $2.5 \mu \mathrm{mol} / \mathrm{L}$ of Rock inhibitor or PBS for 24 hours. For quantification, 100 cells per condition were counted. If a cell contained co-localization of cortactin and actin it was counted as invadopodia positive. The Student $t$ test was performed using the corrected means of the individual experiments $\left({ }^{*}<.05,{ }^{* *}<.01,{ }^{* \star *}<.001\right)$. Data are presented as means \pm SEM. 

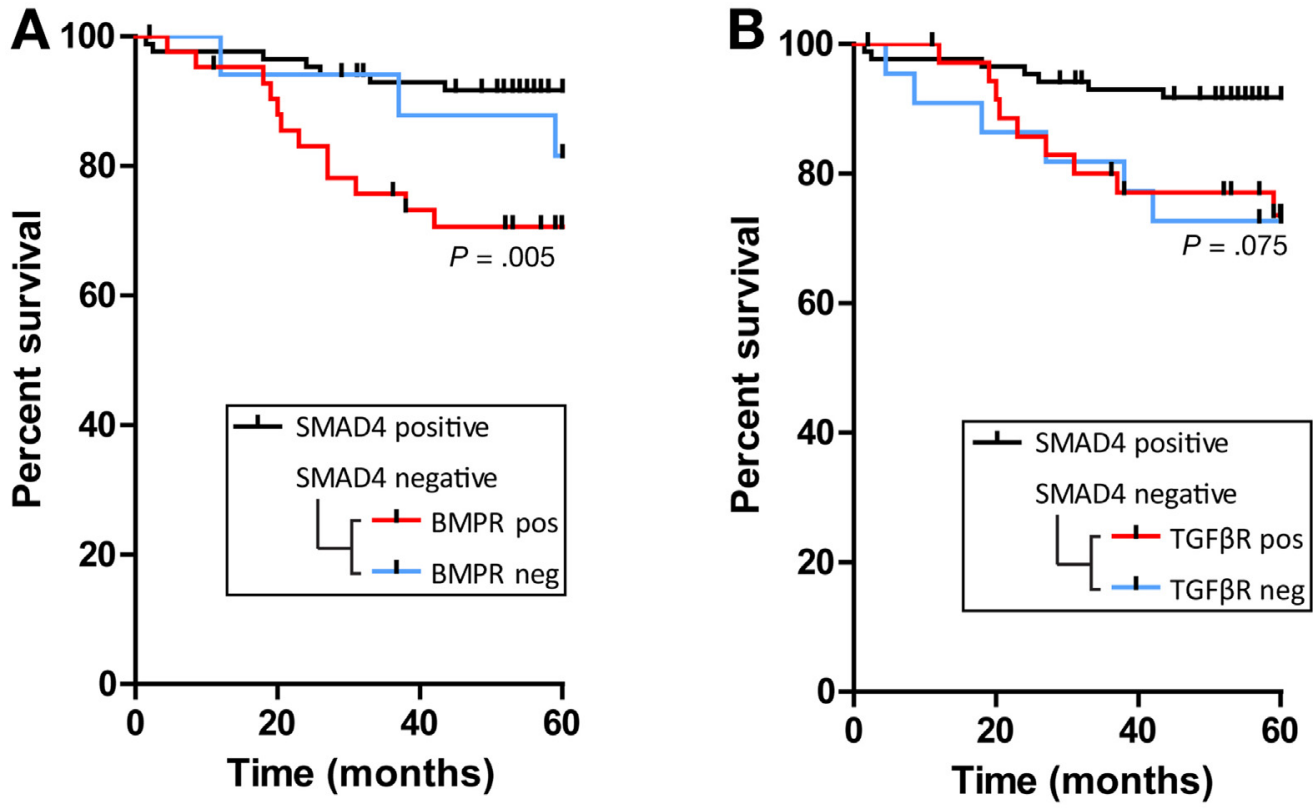

C

Epithelial-like

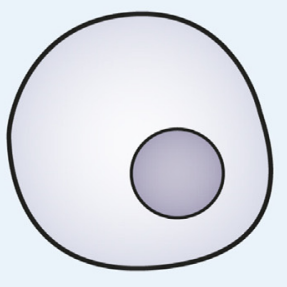

SMAD4 loss

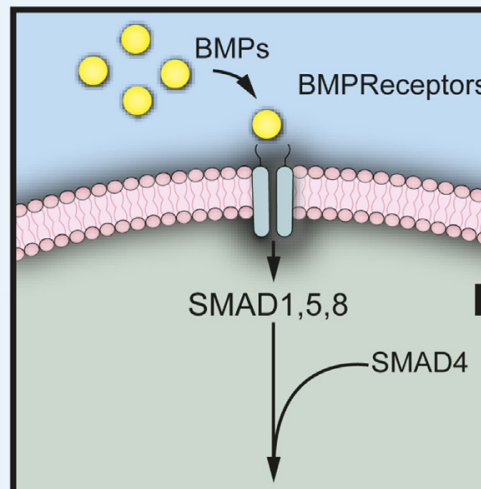

Differentiation / apoptosis

SMAD4-dependent BMP signalling

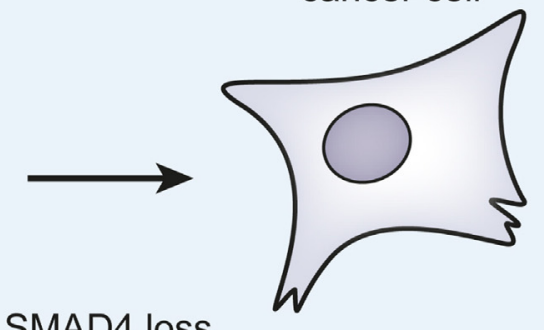

Mesenchymal-like cancer cell

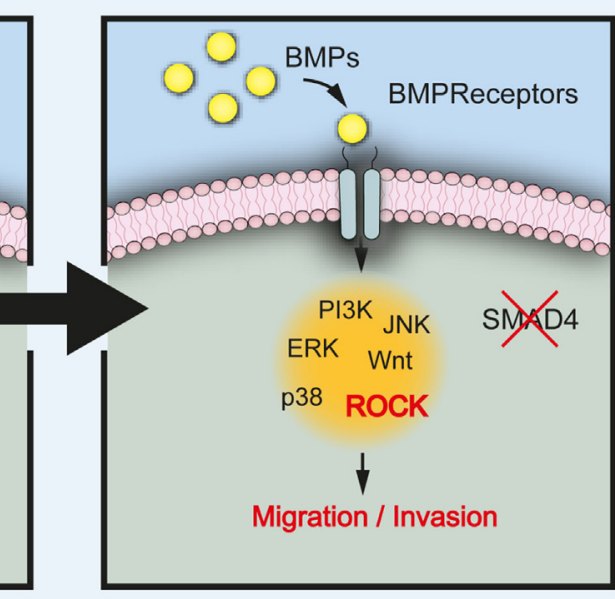

SMAD4-independent BMP signalling
Figure 6. The influence of BMP-receptor expression in SMAD4-negative cancers. (A) CRC tissue from 145 patients was stained for SMAD4, BMPR1A, BMPR1B, and BMPR2 using immunohistochemistry in a tissue microarray. Three cores per cancer were evaluated. For scoring methods and patient information see the Supplementary Materials and Methods section. The graph shows a KaplanMeier survival curve based on SMAD4 and BMPreceptor expression. SMAD4 loss leads to poorer survival. Closer investigation of the SMAD4negative group showed that a subgroup of patients with cancers that expressed BMP receptors had a poorer prognosis than patients who had reduced BMP-receptor expression. (C) Similar analysis as in panel $B$, but based on the expression levels of $\mathrm{TGF} \beta$ receptors (1 and 2) instead of BMP receptors. 


\section{Supplementary Material}

Note: To access the supplementary material accompanying this article, visit the online version of Gastroenterology at www.gastrojournal.org, and at http://dx.doi.org/10.1053/ j.gastro.2014.03.052.

\section{References}

1. Kodach LL, Wiercinska E, de Miranda NF, et al. The bone morphogenetic protein pathway is inactivated in the majority of sporadic colorectal cancers. Gastroenterology 2008;134:1332-1341.

2. Kodach LL, Bleuming SA, Musler AR, et al. The bone morphogenetic protein pathway is active in human colon adenomas and inactivated in colorectal cancer. Cancer 2008;112:300-306.

3. Miyaki M, lijima T, Konishi M, et al. Higher frequency of Smad4 gene mutation in human colorectal cancer with distant metastasis. Oncogene 1999;18:3098-3103.

4. Papageorgis $P$, Cheng K, Ozturk S, et al. Smad4 inactivation promotes malignancy and drug resistance of coIon cancer. Cancer Res 2011;71:998-1008.

5. Cui W, Fowlis DJ, Bryson S, et al. TGFbeta1 inhibits the formation of benign skin tumors, but enhances progression to invasive spindle carcinomas in transgenic mice. Cell 1996;86:531-542.

6. Derynck R, Zhang YE. Smad-dependent and Smadindependent pathways in TGF-beta family signalling. Nature 2003;425:577-584.

7. Massague J. TGFbeta in Cancer. Cell 2008;134:215-230.

8. Adorno $\mathbf{M}$, Cordenonsi M, Montagner $\mathbf{M}$, et al. A Mutant-p53/Smad complex opposes p63 to empower TGFbeta-induced metastasis. Cell 2009;137:87-98.

9. Zhang B, Halder SK, Kashikar ND, et al. Antimetastatic role of Smad4 signaling in colorectal cancer. Gastroenterology 2010;138:969-980.

10. Hardwick JC, van den Brink GR, Bleuming SA, et al. Bone morphogenetic protein 2 is expressed by, and acts upon, mature epithelial cells in the colon. Gastroenterology 2004;126:111-121.

11. Beck SE, Jung BH, Fiorino A, et al. Bone morphogenetic protein signaling and growth suppression in colon cancer. Am J Physiol Gastrointest Liver Physiol 2006;291: G135-G145.

12. Howe JR, Bair JL, Sayed MG, et al. Germline mutations of the gene encoding bone morphogenetic protein receptor 1A in juvenile polyposis. Nat Genet 2001;28: 184-187.

13. Houlston RS, Webb E, Broderick P, et al. Meta-analysis of genome-wide association data identifies four new susceptibility loci for colorectal cancer. Nat Genet 2008; 40:1426-1435.

14. Tomlinson IP, Carvajal-Carmona LG, Dobbins SE, et al. Multiple common susceptibility variants near BMP pathway loci GREM1, BMP4, and BMP2 explain part of the missing heritability of colorectal cancer. PLoS Genet 2011;7:e1002105.

15. He XC, Zhang J, Tong WG, et al. BMP signaling inhibits intestinal stem cell self-renewal through suppression of Wnt-beta-catenin signaling. Nat Genet 2004;36: 1117-1121.

16. Lombardo $Y$, Scopelliti A, Cammareri $P$, et al. Bone morphogenetic protein 4 induces differentiation of colorectal cancer stem cells and increases their response to chemotherapy in mice. Gastroenterology 2011;140: 297-309.

17. Deng H, Ravikumar TS, Yang WL. Overexpression of bone morphogenetic protein 4 enhances the invasiveness of Smad4-deficient human colorectal cancer cells. Cancer Lett 2009;281:220-231.

18. Zonnevylle AC, van Tol RF, Liv N, et al. Integration of a high-NA light microscope in a scanning electron microscope. J Microsc 2013;252:58-70.

19. Liv N, Zonnevylle AC, Narvaez AC, et al. Simultaneous correlative scanning electron and high-NA fluorescence microscopy. PLoS One 2013;8:e55707.

20. Murphy DA, Courtneidge SA. The 'ins' and 'outs' of podosomes and invadopodia: characteristics, formation and function. Nat Rev Mol Cell Biol 2011;12:413-426.

21. Diks SH, Kok K, O'Toole T, et al. Kinome profiling for studying lipopolysaccharide signal transduction in human peripheral blood mononuclear cells. J Biol Chem 2004;279:49206-49213.

22. Tuynman JB, Vermeulen L, Boon EM, et al. Cyclooxygenase-2 inhibition inhibits c-Met kinase activity and Wnt activity in colon cancer. Cancer Res 2008;68: 1213-1220.

23. Narumiya S, Ishizaki T, Uehata M. Use and properties of ROCK-specific inhibitor Y-27632. Methods Enzymol 2000;325:273-284.

24. Roth AD, Delorenzi M, Tejpar S, et al. Integrated analysis of molecular and clinical prognostic factors in stage II/III colon cancer. J Natl Cancer Inst 2012;104:1635-1646.

25. Voorneveld PW, Jacobs RJ, de Miranda NF, et al. Evaluation of the prognostic value of PSMAD immunohistochemistry in colorectal cancer. Eur J Cancer Prev 2013;22:420-424.

26. Kang MH, Kim JS, Seo JE, et al. BMP2 accelerates the motility and invasiveness of gastric cancer cells via activation of the phosphatidylinositol 3-kinase (PI3K)/Akt pathway. Exp Cell Res 2010;316:24-37.

27. Theriault BL, Shepherd TG, Mujoomdar ML, et al. BMP4 induces EMT and Rho GTPase activation in human ovarian cancer cells. Carcinogenesis 2007;28: 1153-1162.

28. Hardwick JC, Kodach LL, Offerhaus GJ, et al. Bone morphogenetic protein signalling in colorectal cancer. Nat Rev Cancer 2008;8:806-812.

29. Wakefield LM, Hill CS. Beyond TGFbeta: roles of other TGFbeta superfamily members in cancer. Nat Rev Cancer 2013;13:328-341.

30. Muraoka-Cook RS, Dumont N, Arteaga CL. Dual role of transforming growth factor beta in mammary tumorigenesis and metastatic progression. Clin Cancer Res 2005; 11:937s-943s.

31. Yilmaz M, Christofori G. EMT, the cytoskeleton, and cancer cell invasion. Cancer Metastasis Rev 2009;28: 15-33. 
32. Nakaya Y, Sukowati EW, Wu Y, et al. RhoA and microtubule dynamics control cell-basement membrane interaction in EMT during gastrulation. Nat Cell Biol 2008; 10:765-775.

33. Moreno-Bueno G, Portillo F, Cano A. Transcriptional regulation of cell polarity in EMT and cancer. Oncogene 2008;27:6958-6969.

34. Grijelmo C, Rodrigue C, Svrcek M, et al. Proinvasive activity of BMP-7 through SMAD4/src-independent and ERK/Rac/JNK-dependent signaling pathways in colon cancer cells. Cell Signal 2007;19:1722-1732.

35. Johnsen IK, Kappler R, Auernhammer CJ, et al. Bone morphogenetic proteins 2 and 5 are down-regulated in adrenocortical carcinoma and modulate adrenal cell proliferation and steroidogenesis. Cancer Res 2009; 69:5784-5792.

36. Konstantinidis G, Moustakas A, Stournaras C. Regulation of myosin light chain function by BMP signaling controls actin cytoskeleton remodeling. Cell Physiol Biochem 2011;28:1031-1044.

37. Groysman M, Shoval I, Kalcheim C. A negative modulatory role for rho and rho-associated kinase signaling in delamination of neural crest cells. Neural Dev 2008;3:27.

38. Wang YK, Yu X, Cohen DM, et al. Bone morphogenetic protein-2-induced signaling and osteogenesis is regulated by cell shape, RhoA/ROCK, and cytoskeletal tension. Stem Cells Dev 2012;21:1176-1186.

39. Lee-Hoeflich ST, Causing CG, Podkowa M, et al. Activation of LIMK1 by binding to the BMP receptor, BMPRII, regulates BMP-dependent dendritogenesis. EMBO J 2004;23:4792-4801.

40. Fujita $H$, Fukumoto $Y$, Saji $K$, et al. Acute vasodilator effects of inhaled fasudil, a specific Rho-kinase inhibitor, in patients with pulmonary arterial hypertension. Heart Vessels 2010;25:144-149.

41. Shibuya M, Suzuki Y, Sugita K, et al. Effect of AT877 on cerebral vasospasm after aneurysmal subarachnoid hemorrhage. Results of a prospective placebo-controlled double-blind trial. J Neurosurg 1992;76:571-577.

42. Wei L, Roberts W, Wang L, et al. Rho kinases play an obligatory role in vertebrate embryonic organogenesis. Development 2001;128:2953-2962.

43. Walther A, Johnstone E, Swanton C, et al. Genetic prognostic and predictive markers in colorectal cancer. Nat Rev Cancer 2009;9:489-499.

Authors names in bold designate shared co-first author.

Received September 27, 2013. Accepted March 30, 2014.

Reprint requests

Address requests for reprints to: James Hardwick, MD, Leiden University Medical Center, Leiden University Medical Center, Albinusdreef 2, Leiden 2300RC, The Netherlands.

\section{Acknowledgments}

The authors would like to thank the following: Dr E. L. Kaijzel and MSc Y. H Cheung for their support with developing the orthotopic mouse model, and Dr S. Lam for helping with the short hairpin RNA transduction.

The study was approved by the investigator's institutional review board (Leiden University Medical Center).

\section{Conflicts of interest}

These authors disclose the following: A. Christiaan Zonnevylle and Jacob Hoogenboom are shareholders and members of the advisory board to DELMIC, which is developing a commercial product based on the prototype SCLEM microscope used in this study. The remaining authors disclose no conflicts.

\section{Funding}

Supported by The Netherlands Digestive Diseases Foundation (P.V. and J.H.), and by the Dutch Cancer Foundation (KWF, UL 2011-5089 to L.L.K.). 


\section{Supplementary Materials and Methods}

\section{Cell Culture}

SW480, HT29, DLD1, and HCT116 colon cancer cell lines were obtained from the American Type Culture Collection (Manassas, VA) and cultured in Dulbecco's modified Eagle medium (Gibco, Paisley, Scotland) with $4.5 \mathrm{~g} / \mathrm{L}$ glucose and $580 \mathrm{mg} / \mathrm{L}$ L-glutamine. This was supplemented with penicillin $(50 \mathrm{U} / \mathrm{mL})$ and streptomycin $(50 \mu \mathrm{g} / \mathrm{mL})$ and with $10 \%$ fetal calf serum (Gibco) unless stated otherwise. HCT116 SMAD4-/- cells were kindly provided by Dr Bert Vogelstein (Johns Hopkins University, Baltimore, MD). HCT116 SMAD4-/- cells were cultured in Dulbecco's modified Eagle medium supplemented with $0.4 \mathrm{mg} / \mathrm{mL}$ G418 and $0.1 \mathrm{mg} / \mathrm{mL}$ hygromycin $\mathrm{B}$. All in vitro experiments were performed on cells growing exponentially.

\section{Activation or Inhibition of BMP Signaling}

Activation. Treatment with BMP-2 ligand (100 ng/mL) (BD Biosciences) dissolved in Dulbecco's modified Eagle medium supplemented with $1 \%$ fetal calf serum was compared with the same volume of PBS dissolved in Dulbecco's modified Eagle medium supplemented with 1\% fetal calf serum, or transfection of a pcDNA4/TO plasmid (Invitrogen) expressing BMPR2 was compared with transfection of an empty vector pcDNA4/TO.

Inhibition. Recombinant human noggin (500 ng/mL) (BD Biosciences) or the small molecule LDN-193189 ( $5 \mathrm{nmol} / \mathrm{L}$ ) (Selleckchem, Houston, TX) in culture medium. The controls were PBS and dimethyl sulfoxide, respectively, added in the same volume to the culture medium.

\section{Transfection, Luciferase Reporter Assay, and Small Interfering RNA Knockdown}

Cells were transfected transiently with either a pcDNA4/ TO*BMPR2-expressing plasmid, a pcDNA4/TO*TGF $\beta$ R2expressing plasmid, or a pcDNA4/TO control vector (Invitrogen). The efficiency of the transfection was evaluated by co-transfection with a pmaxGFP control vector (Amaxa $\mathrm{GmbH}$, Cologne, Germany) and the measurement of GFPpositive cells, which was at least $70 \%$. The activity of canonical BMP and $\mathrm{TGF} \beta$ signaling was measured using co-transfection of BRE-Luc vector or CAGA-Luc vector, respectively, and a cytomegalovirus promoter-driven Renilla luciferase vector (Promega, Leiden, The Netherlands). Transfections were performed using Lipofectamine 2000 (Invitrogen). Twenty-four hours after transfection the luciferase activity was assayed using a Dual-Glo Luciferase Assay System (Promega) on a Luminometer (Berthold Technologies, Bad Wildbad, Germany). Each firefly luciferase value was corrected for its co-transfected renilla luciferase value.

For small interfering RNA knockdown of BMP receptors, cells were transfected with either small interfering RNA against one of the BMP receptors (BMPR1A, BMPR1B, or BMPR2), or scrambled small interfering RNA (all Ambion, Invitrogen) using Lipofectamine 2000 (Invitrogen) (BMPR1A Ambion Silencer Select Pre-designed siRNA ID: s280, BMPR1B Ambion Silencer Select Pre-designed siRNA ID: s2041, and BMPR2 Ambion Silencer Select Pre-designed siRNA ID: s2045).

\section{Stable Short Hairpin RNA-Mediated Knockdown of SMAD4}

Lentiviral constructs expressing short hairpin RNAs targeting SMAD4 (TRCN0000040028) and a nontargeting control construct (SHC002) were obtained from the Sigma mission short hairpin RNA library (Sigma-Aldrich, St. Louis, MO). Production of lentiviruses by transfection into 293T cells has been described earlier. ${ }^{1}$ Cells were transduced in the presence of $8 \mu \mathrm{g} / \mathrm{mL}$ polybrene (Sigma-Aldrich). Cells were selected using puromycin.

\section{Wound Healing Assay}

Cells were plated in 6-well plates (Corning, Inc) and grown in a monolayer until $70 \%-80 \%$ confluent. At this point, a scratch was made using the tip of a micropipette. Bright-field images were obtained at 0 hours and after 24 hours and cell migration was calculated using ImageJ software version 1.46 (National Institutes of Health, Bethesda, MD; available: rsbweb.nih.gov/ij/) as the ratio of the wound closure relative to the initial wound.

\section{Roundness}

Phase-contrast images of HCT116 and HCT116 SMAD4-/cells were obtained using a Zeiss Axiovert 200m (Sliedrecht, The Netherlands). Images were analyzed using ImageJ software and the roundness was calculated using the following principle. Roundness (R) is based on a circularity ratio between the surface area of the cell and a perfect circle that has the same perimeter as the cell. The roundness can be calculated using 2 variables, namely surface area (A) and the perimeter $(\mathrm{P})$. The given formulas for a perfect circle with $\mathrm{R}=1$ are as follows: $\mathrm{A}=\pi \mathrm{r}^{2}$, and $\mathrm{P}=\pi \mathrm{r}$ or $\mathrm{r}=\mathrm{P} / 2 \pi$, and then substituting the radius in $\mathrm{A}$ provides the following: $\mathrm{A}=\pi$ $(\mathrm{P} / 2 \pi)^{2} \rightarrow \mathrm{A}=\pi \mathrm{P}^{2} /\left(4 \pi^{2}\right) \rightarrow \mathrm{A}=\mathrm{P}^{2} / 4 \pi$. If the $\mathrm{R}$ is a ratio between the surface area of the test shape and the surface area of a perfect circle then $\mathrm{R}=\mathrm{A}_{\text {cell }} / \mathrm{A}_{\text {circle }}$. With the previous area of a perfect circle filled into the equation it provides the following: $\mathrm{R}=\mathrm{A}_{\text {cell }} /\left(\mathrm{P}^{2} / 4 \pi\right)$ or $\mathrm{R}=4 \pi\left(\mathrm{A} / \mathrm{P}^{2}\right)$.

In this formula, a perfect circle is equal to 1 and a line approaches 0 . The roundness of 100 cells per condition was measured in each experiment.

\section{Kinase Inhibitor Screen}

Cells were grown in 6-well plates. Cells were transfected with either pcDNA or BMPR2 when $60 \%$ confluent, after which the cells were treated with kinase inhibitors (Supplementary Table 1 shows the concentrations). After 24 hours of treatment the cells were lysed using TRIzol and RNA was isolated. A reverse-transcription polymerase chain reaction was performed for the expression of vimentin (see following paragraph for protocol). 


\section{Real-Time Polymerase Chain Reaction}

Total RNA was isolated using TRIzol (Invitrogen) according to the manufacturer's instructions. Complementary DNA was synthesized from $1 \mu \mathrm{g}$ of total RNA using random primers (Promega) and MMLV-reverse transcriptase (Invitrogen). Polymerase chain reaction was performed using the iCycler Thermal Cycler and the iQ5 Multicolor Real-Time Polymerase Chain Reaction Detection System (Bio-Rad, Santa Cruz, CA). Glyceraldehyde-3-phosphate dehydrogenase expression was used to normalize for variance. Details of the primers used are shown in Supplementary Table 2.

\section{Immunoblotting}

Cells were grown in 6-well plates. Cells were washed with PBS and cell lysis buffer (Cell Signaling Technology, Beverly, MA) plus protease inhibitor (Pierce Biotechnology, Rockford, IL) was added. The cells were lysed on ice for 15 minutes, scraped into 1.5-mL tubes (Eppendorf, Hamburg, Germany), sonicated, and centrifuged for 10 minutes at $14,000 \mathrm{rpm}$ at $4^{\circ} \mathrm{C}$. Protein levels were measured with a BCA kit (Pierce Biotechnology) using clear lysates. The protein levels in each sample were equalized, the lysates were mixed with $3 \times$ sodium dodecyl sulfate sample buffer (125 mmol/L Tris/HCl, pH 6.8; 4\% sodium dodecyl sulfate; $3 \% \beta$-mercaptoethanol; $20 \%$ glycerol, bromphenol blue), and were boiled at $97^{\circ} \mathrm{C}$ for 5 minutes. The proteins were separated by sodium dodecyl sulfate-polyacrylamide gel electrophoresis and blotted onto a polyvinylidene difluoride membrane (Millipore, Billerica, MA). The blots were blocked in blocking buffer containing 5\% nonfat dry milk (Bio-Rad) dissolved in Tris-buffered saline supplemented with $0.05 \%$ Tween-20 and washed 3 times in the Tris-buffered saline supplemented with $0.05 \%$ Tween-20. Both primary and secondary antibodies were dissolved in $0.5 \%$ nonfat dry milk. The primary antibody was incubated overnight at $4{ }^{\circ} \mathrm{C}$ (see Supplementary Table 3 for antibodies used and dilutions) in $0.1 \%$ nonfat dry milk- Tris-buffered saline supplemented with $0.05 \%$ Tween-20. Secondary horseradish-peroxidase-linked antibody was incubated for 1 hour at room temperature with $0.1 \%$ nonfat dry milk-Trisbuffered saline supplemented with $0.05 \%$ Tween-20. Blots then were exposed to Lumilight+ (Roche, Basel, Switzerland) chemiluminescent substrate and visualized using a chemiluminescence imager (Bio-Rad).

\section{Immunoprecipitation}

HA tag antibodies (Cell Signaling) were added to the cell lysate (1:150) and incubated with gentle rocking overnight at $4^{\circ} \mathrm{C}$. Afterward, protein A agarose beads (Cell Signaling) $(20 \mu \mathrm{L})$ were added and lysate was incubated with gentle rocking for 3 hours at $4^{\circ} \mathrm{C}$. Lysate was spun down and the pellet was washed 5 times with $500 \mu \mathrm{L}$ of cell lysis buffer. The pellet was resuspended in $20 \mu \mathrm{L} 3 \times$ sodium dodecyl sulfate sample buffer and heated to $97^{\circ} \mathrm{C}$ for 5 minutes. Subsequently, the samples were loaded on a sodium dodecyl sulfate-polyacrylamide gel.

\section{Immunofluorescence}

Alexa Fluor 488 phalloidin was obtained from Invitrogen. Anticortactin (p80/85) (mouse), clone 4F11 was obtained from Millipore. Anti-mouse AlexaFluor 594 was obtained from Invitrogen. For immunofluorescence, cells were adhered to poly-l-lysine-coated (Sigma-Aldrich) coverslips, fixed in $4 \%$ paraformaldehyde, stained in permeabilization buffer (PBS containing 0.05\% Triton X-100 [Sigma-Aldrich, Zwijndrecht, The Netherlands]), and embedded in SlowFade Gold (Invitrogen). Images were obtained on a Leica TCS SP2 laser scanning spectral confocal microscope equipped with 488-nm argon and 543 HeNe lasers (Leica, Mannheim, Germany) and processed using ImageJ software.

\section{Simultaneous Correlative Scanning Electron and High Numeric Aperture Fluorescence Microscopy}

The following section contains a summary of the microscopy set-up. For a complete microscope set-up and explanation of tissue and staining methods we refer to 2 reports by Liv et $\mathrm{al}^{2}$ and Zonnevylle et al. ${ }^{3}$

All imaging experiments were performed on a fluorescence microscope integrated into a commercial Scanning Electron Microscope (Quanta 200 FEG microscope; FEI, Eindhoven, The Netherlands) as developed at Delft University of Technology and DELMIC BV (Delft, The Netherlands). The fluorescence microscope was equipped with a $100 \times 1.4$ numeric aperture objective lens (Nikon CFI Plan Apochromat VC) mounted below the sample holder in the Scanning Electron Microscope chamber, and excitation and emission filters for AlexaFluor 488.

\section{Seeding and Transfection}

ITO-coated microscope slides (thickness \#1, $22 \times 22 \mathrm{~mm}$ with 8-12 $\Omega \mathrm{sq}^{-1}$ or $22 \times 40 \mathrm{~mm}$ with $70-100 \Omega \mathrm{sq}^{-1}$; SPI Supplies, West Chester, PA) were disinfected with $70 \%$ ethanol, placed in culture dishes with the conductive side upward, and incubated with culture medium. The cells were seeded onto the ITO-coated glass slides. When cells reached a confluence of $60 \%$ they were transfected with either pcDNA4/TO or BMPR2 and cultured for 48 hours at $37^{\circ} \mathrm{C}$ in $5 \% \mathrm{CO}_{2}$. Cells then were washed twice with PBS and fixed for 10 minutes with a mixture of $2.5 \%$ paraformaldehyde and $1.25 \%$ glutaraldehyde in $0.1 \mathrm{~mol} / \mathrm{L}$ PBS, pH 7.4. Samples were washed 3 times with PBS after fixation.

\section{Fluorescent Labeling and Immunocytochemistry}

Actin was stained using AlexaFluor 488 phalloidin (Invitrogen) in a 1:40 PBS/1\% bovine serum albumin/0.1\% Triton dilution for 30 minutes according to the manufacturer's instructions. Afterward, samples were washed 3 times with PBS.

For the immunocytochemistry of cortactin, cells were incubated with the primary antibody in PBS/1\% bovine serum albumin $/ 0.1 \%$ Triton (1:200) for 30 minutes at room temperature and afterward were washed 3 times with PBS. 
The cells then were incubated with the secondary antibody (1:200) diluted in PBS/1\% bovine serum albumin/0.1\% Triton for 20 minutes at room temperature and then washed again 3 times with PBS. The primary antibody used was anticortactin (p80/85) (mouse), clone 4F11 (Millipore), and the secondary antibody was AlexaFluor 594 goat antimouse IgG $(\mathrm{H}+\mathrm{L})$ (Invitrogen). To remove any remaining salt residue the cells were washed 3 times with $\mathrm{dH}_{2} \mathrm{O}$ and left in $\mathrm{dH}_{2} \mathrm{O}$ at $4^{\circ} \mathrm{C}$ overnight.

\section{Kinase Activity Analysis Using Pepchip Peptide Arrays}

Kinome profiling using peptide arrays exploits the substrate specificity of individual kinases to infer their activity from changes in the phosphorylation of an array of immobilized peptide kinase substrates. In our approach, we used peptide arrays containing 960 peptides, each representing a fully annotated, disease-related kinase phosphorylation site, which were spotted on Hydrogel-coated glass in triplicate (the spotting procedure is described by Diks et $\mathrm{al}^{4}$ ). The sequence of the peptides involved as well as the source proteins from which these peptides were derived can be found in more detail at http://www.pepscan.com/presto/ files/pepchip/PepChip-Kinomics-Map.zip. Procedures for performing kinome arrays have been described in detail elsewhere. ${ }^{5,6}$ Briefly, cells were lysed in $50 \mu \mathrm{L}$ lysis buffer (20 mmol/L Tris-HCl pH 7.5, $150 \mathrm{mmol} / \mathrm{L} \mathrm{NaCl}, 1 \mathrm{mmol} / \mathrm{L}$ EDTA, $1 \mathrm{mmol} / \mathrm{L}$ ethylene glycol-bis( $\beta$-aminoethyl ether)$N, N, N^{\prime}, N^{\prime}$-tetraacetic acid, $1 \%$ Triton X-100, $2.5 \mathrm{mmol} / \mathrm{L}$ sodium pyrophosphate, $1 \mathrm{mmol} / \mathrm{L} \mathrm{MgCl}_{2}, 1 \mathrm{mmol} / \mathrm{L}$ glycerophosphate, $1 \mathrm{mmol} / \mathrm{L} \mathrm{Na}_{3} \mathrm{VO}_{4}, 1 \mathrm{mmol} / \mathrm{L} \mathrm{NaF}, 1 \mu \mathrm{g} / \mathrm{mL}$ leupeptin, $1 \mu \mathrm{g} / \mathrm{mL}$ aprotinin, and $1 \mathrm{mmol} / \mathrm{L}$ phenylmethylsulfonyl fluoride) and $10 \mathrm{~mL}$ of the peptide array incubation mix $(50 \%$ glycerol, $50 \mu \mathrm{mol} / \mathrm{L}$ adenosine triphosphate, $0.05 \%$ vol/vol Brij-35, $0.25 \mathrm{mg} / \mathrm{mL}$ bovine serum albumin, ${ }^{33} \mathrm{P}-\gamma$-adenosine triphosphate [1 $\left.\mathrm{MBq}\right]$ ) was added to the filtered lysates and the mixture was loaded onto the microarray chip and allowed to phosphorylate the peptide substrates for 90 minutes at $37^{\circ} \mathrm{C}$. The chips were washed twice with TBS $0.1 \%$ Triton X-100, twice in $2 \mathrm{~mol} / \mathrm{L} \mathrm{NaCl}$, and twice in demineralized water and airdried. The slides then were exposed to a phosphor-imager plate for 72 hours and acquisition of the peptide array was performed using a phosphor-imager (Storm; Amersham Biosciences, Stockholm, Sweden). Levels of incorporated radioactivity, which corresponded to the phosphorylation status, were quantified by the array software Scanalyze (Eisen Software) and exported to Microsoft Excel. As a control, further slides were incubated with ${ }^{33} \mathrm{P}$ $\gamma$-adenosine triphosphate $(1 \mathrm{MBq})$ without cell lysate to show that the signal observed represented kinasedependent covalent transfer of the terminal phosphor atom.

For data analysis, every peptide was first given an "on" call or "off" call (Markov state analysis). To do this, an average signal for each peptide first was calculated using the 3 replicates to yield an aggregate data set for each of the experimental conditions. Subsequently, for each of the aggregate data sets, an "on" call or an "off" call was given to each peptide substrate (Markov state analysis). To do this, we assumed that the subset of signals representing the $1-\mathrm{e}^{-1}$ fraction of peptides having the lowest phosphorylation of all peptides contained pure noise and did not represent meaningful phosphorylation. The distribution of this noise was fitted as a single exponent, using the amplitude-sorted row number of these substrates as the $\mathrm{X}$ domain of the distribution and this single exponent was assumed to describe noise for the entire data set for this experimental condition. Now, for all data points within the subset, when the actual amplitude observed minus 1,96 the standard deviation was in excess of the value expected from the distribution describing the noise, a substrate was given an "on" call. For further analysis, peptides were grouped in signal transduction categories and the number of "on" calls in each category was compared for the different experimental conditions and subjected to Galton statistics. Attribution of peptides to signal transduction categories as well as the number of "on" calls in each category can be found in Supplementary Figure 3. Results then were grouped into 8 broad biological processes for first analysis by contrasting activities in these broad groups and then mined for detailed elucidation of the signaling evoked by BMPR2 in SMAD4negative cancer cells.

\section{Orthotopic Metastasis Mouse Model}

Development of luciferase expressing cell line. HT29-cells were stably transfected with a pGL4 vector expressing firefly luciferase controlled by a CAGGS promoter. The transfected cells were selected using G418 $(500 \mu \mathrm{g} / \mathrm{mL})$.

Intrasplenic cell injection. Liver metastasis were generated by injecting $0.5 * 10^{6}$ HT29 cells expressing luciferase dissolved in $50 \mu \mathrm{L}$ of medium:Matrigel (1:1) into the spleens of 6-week-old immunocompromised CD1 nude mice (males). Mice were purchased from Charles River Laboratories International, Inc (Wilmington, MA).

The mice were anesthetized with isoflurane. A dorsal subcostal incision was made to expose the spleen. The spleen was exteriorized and placed on gauze soaked in PBS. The volume $(50 \mu \mathrm{L})$ of tumor cell suspension was injected slowly into the spleen using a 25 -gauge needle.

Treatment and analysis. The mice were treated by intraperitoneal injection with $2.5 \mathrm{mg} / \mathrm{kg} \mathrm{Y}-27632$ (R\&D Systems) dissolved in PBS $(\mathrm{n}=9)$ or with PBS $(\mathrm{n}=9)$ every other day. Weekly scans were performed by intraperitoneal injection of $100 \mu \mathrm{L}$ luciferin $(25 \mathrm{mg} / \mathrm{mL})$ and tumor formation was visualized using the IVIS Lumina Imaging system (Xenogen, Hopkinton, MA). Living Image software (Caliper, Hopkinton, MA) was used to analyze and quantify the scans. After 7 weeks the mice were euthanized. The weight and volume of the livers was determined for each mouse.

\section{Tissue Microarray}

A tissue microarray containing colorectal cancer tissue from 145 was constructed from formalin-fixed, paraffinembedded tissues from the archives of the Pathology 
Department at the Academic Medical Centre and the Pathology Department at the Leiden University Medical Center. Three 2-mm cores of tissue from each patient were included on the array. One core from the corresponding normal colon and 2 cores from carefully selected representative areas of the tumor were included (Supplementary Table 4).

\section{Immunohistochemistry}

SMAD4, BMPR2, and TGF $\beta$ R2. Sections were deparaffinized, rehydrated in graded ethanol, and immersed in $0.3 \%$ hydrogen peroxide in methanol for 20 minutes to block endogenous peroxidase activity and antigen retrieval was performed in $1 \times$ Tris/EDTA, pH 9.0, for 30 minutes at $97^{\circ} \mathrm{C}$. Nonspecific binding sides were blocked with $10 \%$ normal goat serum for 20 minutes. Primary antibody incubation was performed for 1 hour at room temperature (diluted in PBS/0.1\% Triton/1\% bovine serum albumin; see Supplementary Table 5 for concentration). Subsequently, the LSAB + System-horseradish peroxidase detection system (Dako) was used. Peroxidase activity was detected with fastDAB (Sigma-Aldrich).

BMPR1A, BMPR1B, and TGF $\beta$ R1. Sections were deparaffinized, rehydrated in graded ethanol, and immersed in $0.3 \%$ hydrogen peroxide in methanol for 30 minutes. Antigen retrieval was performed by heating for 10 minutes to $97^{\circ} \mathrm{C}$ in sodium citrate, $\mathrm{pH} 6.0$, and nonspecific binding sides were blocked by incubation with $10 \mathrm{mmol} / \mathrm{L}$ Tris, $5 \mathrm{mmol} / \mathrm{L}$ EDTA, $0.15 \mathrm{~mol} / \mathrm{L} \mathrm{NaCl}, 0.25 \%$ gelatin, and $0.05 \%$ Tween 20, pH 8.0 for 10 minutes. Antibodies were diluted in PBS/0.1\% Triton/1\% bovine serum albumin (see Supplementary Table 5 for concentration). Incubation took place overnight at $4^{\circ} \mathrm{C}$ and subsequently the LSAB+ System-horseradish-peroxidase detection system (Dako) was used. Peroxidase activity was detected with fastDAB (Sigma-Aldrich).

\section{TMA Analysis}

Analysis was performed in a blinded fashion by 2 investigators independently. SMAD4 expression was scored according to previously described methods. ${ }^{7}$ SMAD4 staining was scored as follows: 0 , no staining, 1, weak nuclear staining or negative nuclear and weak intracytoplasmic staining in less than $10 \%$ of the cells; and 2 , moderate to strong nuclear staining in more than $10 \%$ of the cells. The scoring of $\mathrm{TGF} \beta$ and BMP-receptor staining (BMPR1A, BMPR1B, BMPR2, TGF $\beta$ R1, and TGF $\beta$ R2) was based on both staining intensity and the percentage of tumor cells stained as outlined in Supplementary Table 6.

\section{Statistical Analysis}

Statistical analysis was performed using the 2-tailed Student $t$ test, and a $P$ value less than .05 was considered statistically significant. All experiments were performed with a minimum of 3 independent experiments. Data are shown as the mean \pm SEM. Statistical analysis was performed with Prism 5 for Windows (GraphPad Software, Inc, La Jolla, CA) using the Student $t$ test and the chi-square test, and with PASW Statistics 18 for Windows (SPSS, Inc, Armonk, NY) for the Kaplan-Meier analysis and Cox regression. The Student $t$ tests were 2-tailed. A $P$ value less than .05 was considered significant.

\section{References}

1. Carlotti F, Bazuine M, Kekarainen $T$, et al. Lentiviral vectors efficiently transduce quiescent mature 3T3-L1 adipocytes. Mol Ther 2004;9:209-217.

2. Liv N, Zonnevylle AC, Narvaez AC, et al. Simultaneous correlative scanning electron and high-NA fluorescence microscopy. PLoS One 2013;8:e55707.

3. Zonnevylle AC, Van Tol RF, Liv N, et al. Integration of a high-NA light microscope in a scanning electron microscope. J Microsc 2013;252:58-70.

4. Diks SH, Kok K, O'Toole T, et al. Kinome profiling for studying lipopolysaccharide signal transduction in human peripheral blood mononuclear cells. J Biol Chem 2004;279:49206-49213.

5. Tuynman JB, Vermeulen L, Boon EM, et al. Cyclooxygenase-2 inhibition inhibits c-Met kinase activity and Wnt activity in colon cancer. Cancer Res 2008;68: 1213-1220.

6. van Baal JW, Diks SH, Wanders RJ, et al. Comparison of kinome profiles of Barrett's esophagus with normal squamous esophagus and normal gastric cardia. Cancer Res 2006;66:11605-11612.

7. Kodach LL, Wiercinska E, de Miranda NF, et al. The bone morphogenetic protein pathway is inactivated in the majority of sporadic colorectal cancers. Gastroenterology 2008;134:1332-1341. 
A

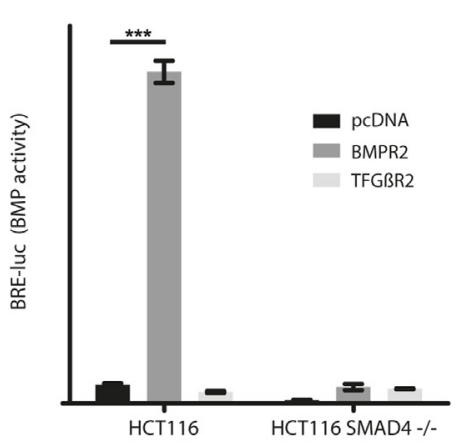

D

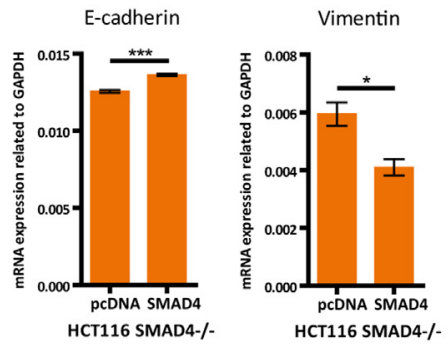

F

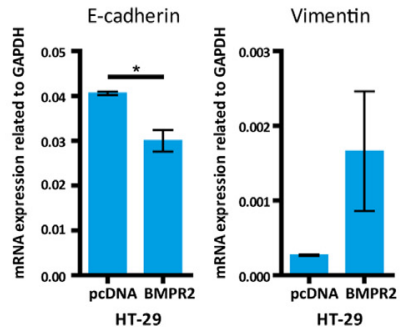

B

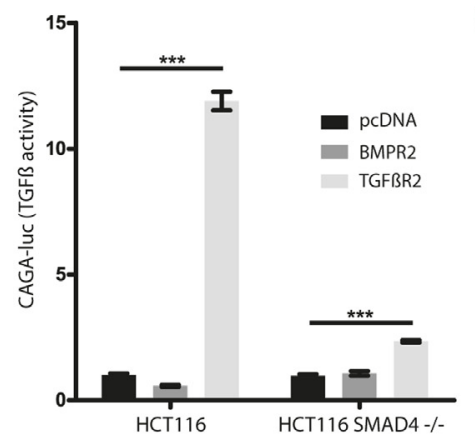

E
C

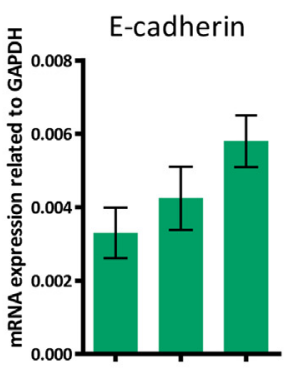

LDN-193189
HCT116 SMAD4-/-

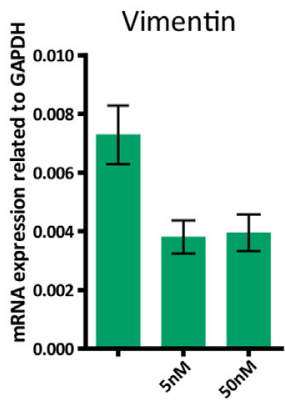

LDN-193189

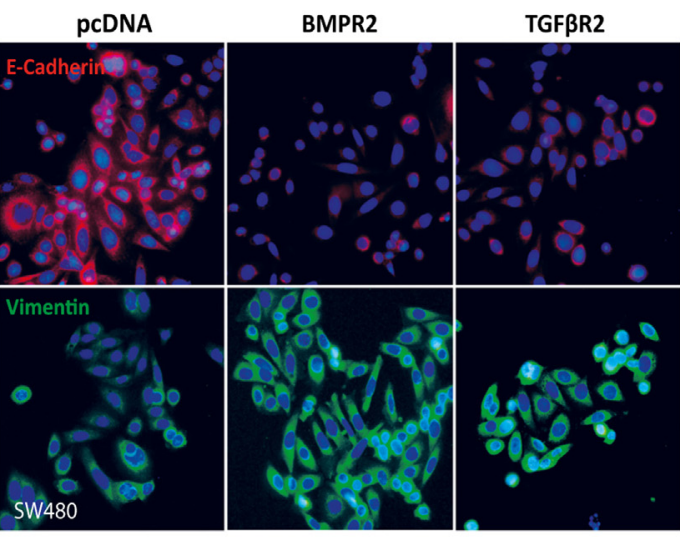

G
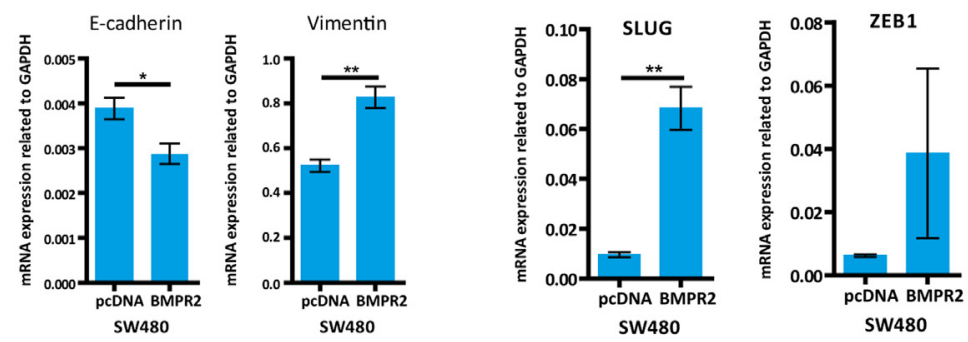

H
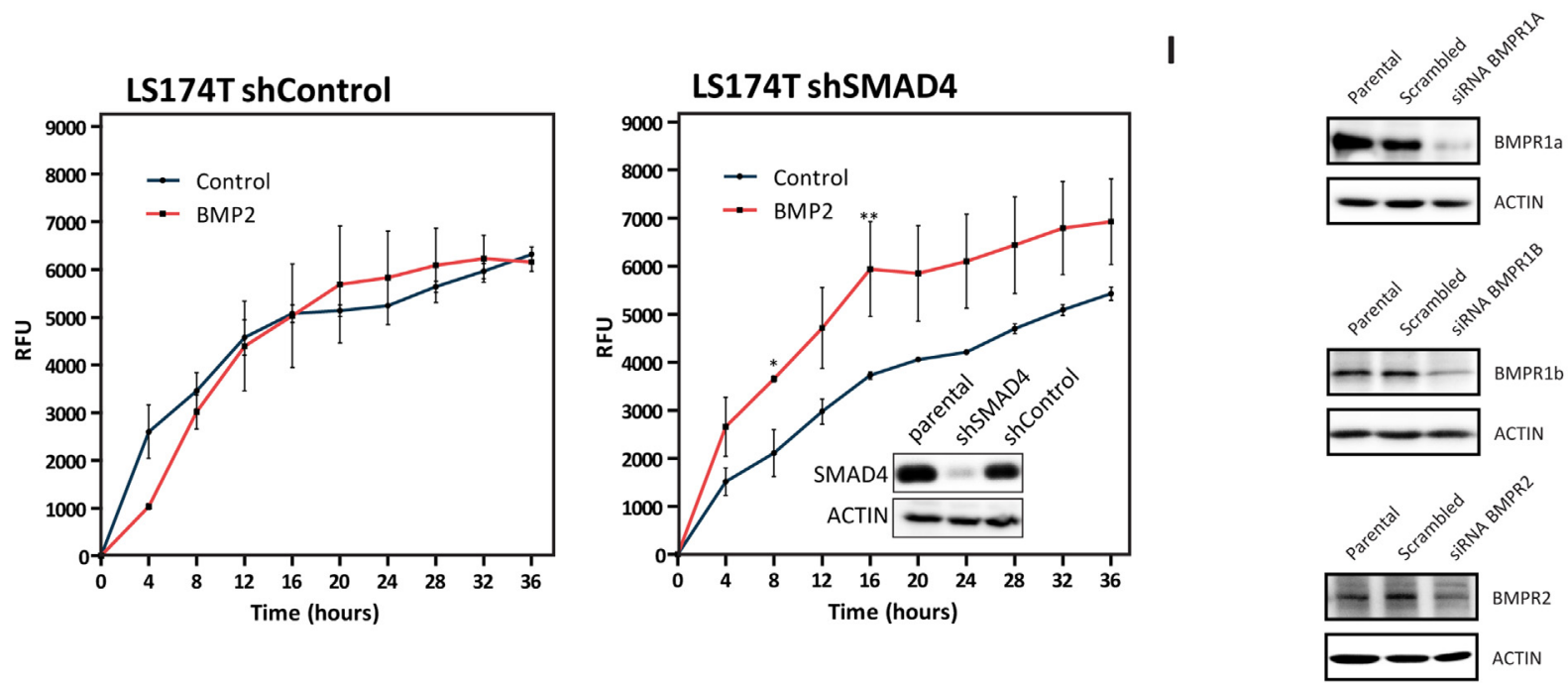


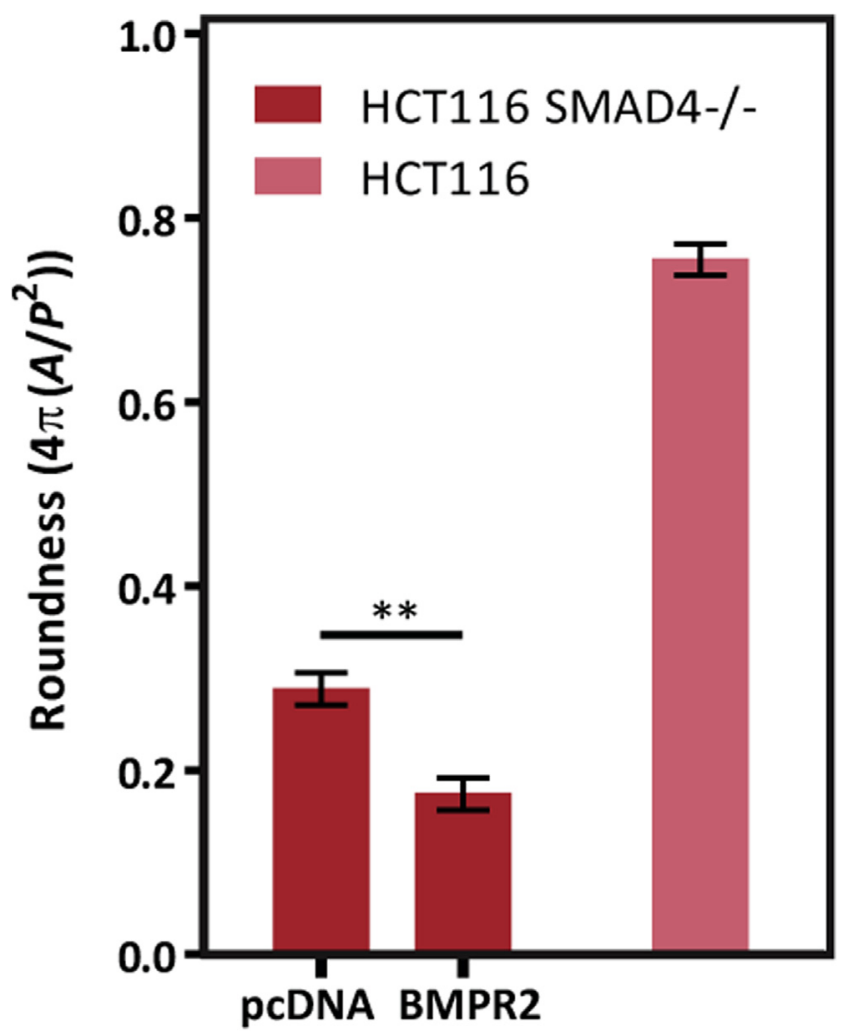

Supplementary Figure 2. HCT116 SMAD4-/- cells were transfected transiently with either BMPR2 or control pcDNA. The roundness was calculated as described in the Supplementary Materials and Methods section. HCT116 cells were used as a SMAD4-positive control. Student $t$ tests were performed as appropriate $\left({ }^{*}<0.05,{ }^{* \star}<0.01,{ }^{* \star *}<0.001\right)$. Data are presented as means \pm SEM.

Supplementary Figure 1. $(A$ and $B)$ HCT116 and HCT116 SMAD4-/- cells were transfected transiently with either BMPR2, TGF- $\beta$ R2, or the empty control plasmid pcDNA. After 24 hours, BMP (BRE-luc) and TGF- $\beta$ (CAGA-luc) activity were measured using luciferase reporter constructs. (C) HCT116 SMAD4-/- cells were treated with $5 \mathrm{nmol} / \mathrm{L}$ and $50 \mathrm{nmol} / \mathrm{L}$ of LDN-193189 for 24 hours and compared with a control. Subsequently, mRNA expression levels of E-cadherin and vimentin were measured using quantitative reverse-transcription polymerase chain reaction. Glyceraldehyde-3-phosphate dehydrogenase (GAPDH) was used a control. $(D)$ HCT116 SMAD4-/- cells were transfected with either pcDNA or a plasmid expressing wild-type SMAD4. mRNA levels of E-cadherin and vimentin were measured using quantitative reverse-transcription polymerase chain reaction. $(E)$ Fluorescent immunocytochemistry for E-cadherin and vimentin in SW480 cells. Cells were transfected with either pcDNA or BMPR2. $(F)$ mRNA expression levels of E-cadherin and vimentin measured using quantitative reverse-transcription polymerase chain reaction in SW480 and HT-29 (SMAD4-negative) cells transfected with either pcDNA or BMPR2. GAPDH was used as a control. (G) SW480 (SMAD4-negative) cells were transfected with either pcDNA or BMPR2. mRNA expression levels of the EMT-associated transcription factors SLUG and ZEB1 were measured using quantitative reverse-transcription polymerase chain reaction. GAPDH was used as a control. $(H)$ Invasion of LS174T and LS174t shSMAD4 cells measured over a 36-hour time period in a Matrigel-Transwell system. Cells were labeled with a fluorescence label Cell tracker, and seeded in the upper chamber of a Transwell system and subsequently treated with $100 \mathrm{ng} / \mathrm{mL}$ BMP2 or PBS (control). (I) Western blot analysis of the small interfering RNA (siRNA) knockdown of BMPR1A, BMPR1B, and BMPR2 in SW480 cells. Actin was used as a loading control. Cells transfected with nontargeting scrambled siRNA were used as a control. Student $t$ tests were performed as appropriate $\left({ }^{*}<0.05,{ }^{* *}<0.01,{ }^{* \star *}<0.001\right)$. Data are presented as means \pm SEM. 
A.

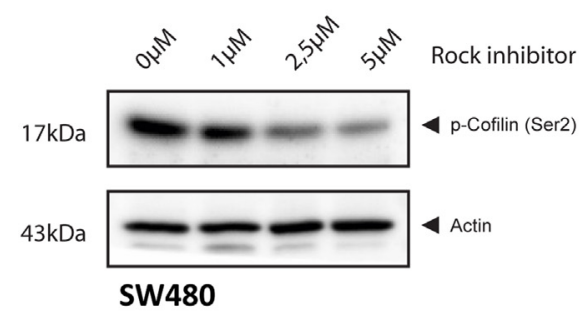

C

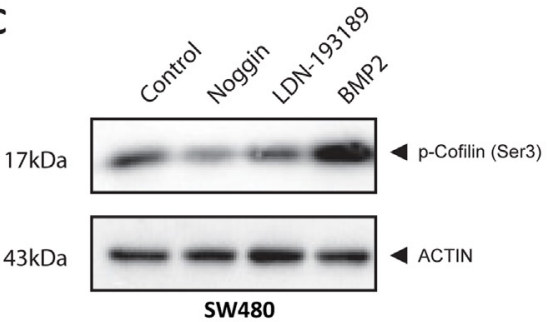

E

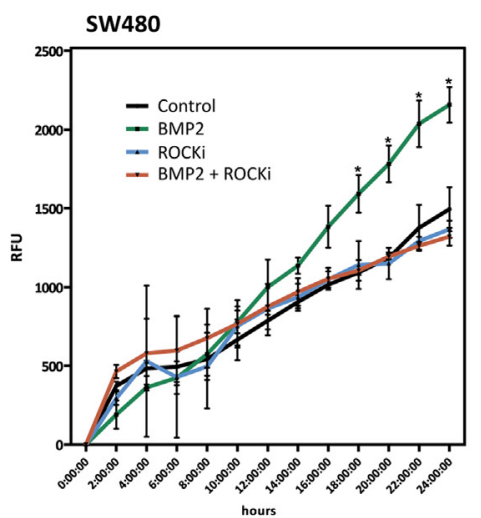

B.

$-\quad-\quad+\quad+\operatorname{ROCKi}(2,5 \mu \mathrm{M})$

$72 \mathrm{kDa}$

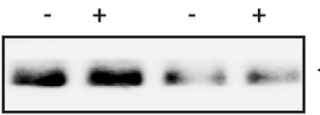

BMPR2

p-LIMK1 (Thr508)/ p-LIMK2 (Thr505)

$17 \mathrm{kDa}$

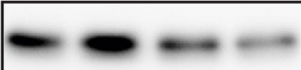

p-Cofilin (Ser2)

$43 \mathrm{kDa}$

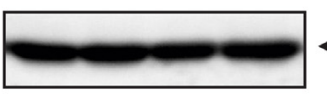

4 Actin

\section{SW480}

D

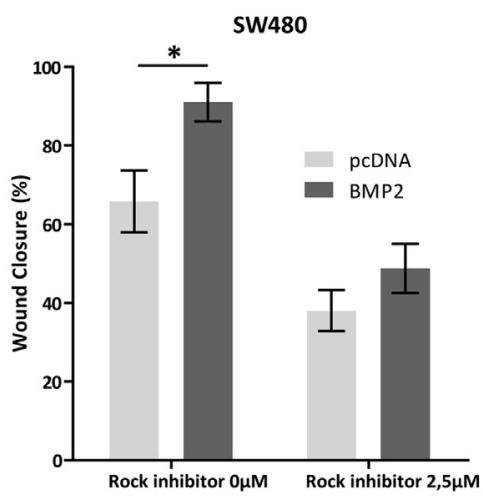

Supplementary Figure 4. (A) SW480 cells were treated with different concentrations of the ROCK inhibitor Y-27632 to evaluate the optimal treatment concentration. Cells were lysed and samples were analyzed by immunoblotting using antibodies against p-cofilin. Actin was used as a loading control. At $2.5 \mu \mathrm{mol} / \mathrm{L}$ the ROCK inhibitor leads to near-maximal inhibition of p-cofilin. (B) SW480 cells were transfected with either BMPR2 or pcDNA. Subsequently, the cells were treated with 2.5 $\mu \mathrm{mol} / \mathrm{L}$ of the ROCK inhibitor Y-27632 in PBS or PBS alone. Cells were lysed and samples were analyzed by immunoblotting. Blots were exposed to antibodies against $\mathrm{p}$-LIMK1/2 and p-cofilin. Actin was used as a loading control. (C) SW480 cells were treated with noggin $(500 \mathrm{ng} / \mathrm{mL}), \mathrm{LDN}-193189(5 \mathrm{nmol} / \mathrm{L})$, or BMP-2 ligands $(100 \mathrm{ng} / \mathrm{mL})$ for 24 hours. Afterward, cells were lysed and immunoblotting for protein expression of $\mathrm{p}$-cofilin was performed. Actin was used as a loading control. (D) SW480 cells were transfected with either pcDNA or BMPR2. Afterward, a wound-healing assay was performed to measure cell migration. The image shows a quantification of the wound closure after 24 hours. (E) Invasion assay of SW480 cells treated with either PBS (control), BMP-2 (100 ng/mL), ROCK inhibitor $(2.5 \mu \mathrm{mol} / \mathrm{L})$, or a combination of BMP-2 (100 $\mathrm{ng} / \mathrm{mL}) \mathrm{plus}$ a ROCK inhibitor $(2.5 \mu \mathrm{mol} / \mathrm{L})$. Student $t$ tests were performed as appropriate $\left({ }^{*}<.05,{ }^{\star *}<.01,{ }^{\star \star *}<.001\right)$. Data are presented as means \pm SEM. 
A

HT-29

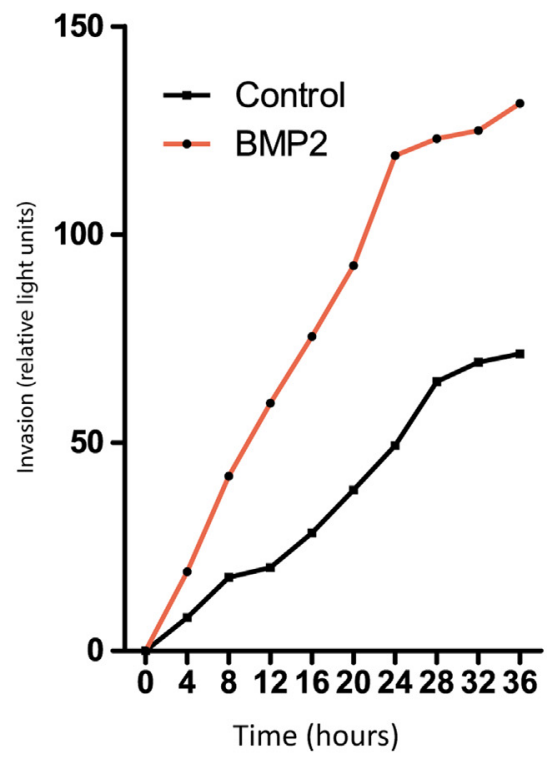

D

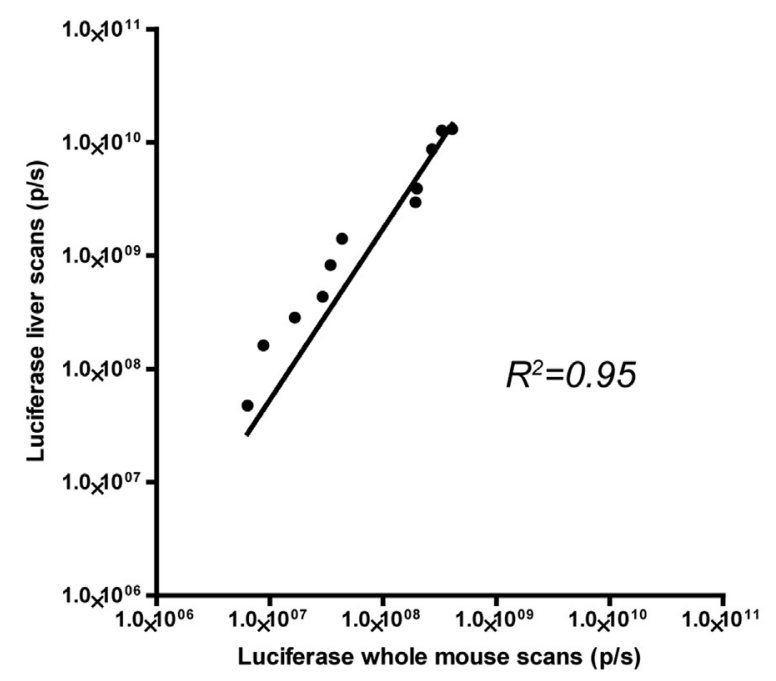

G

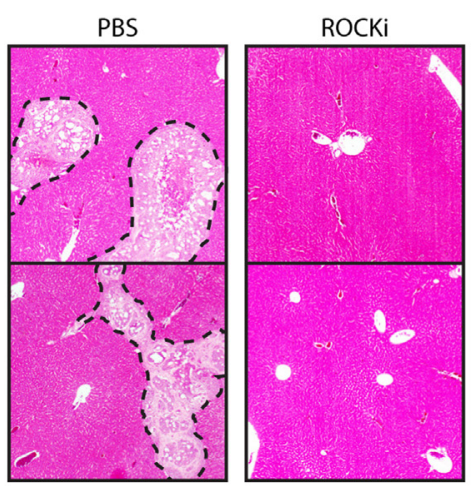

B

HT-29

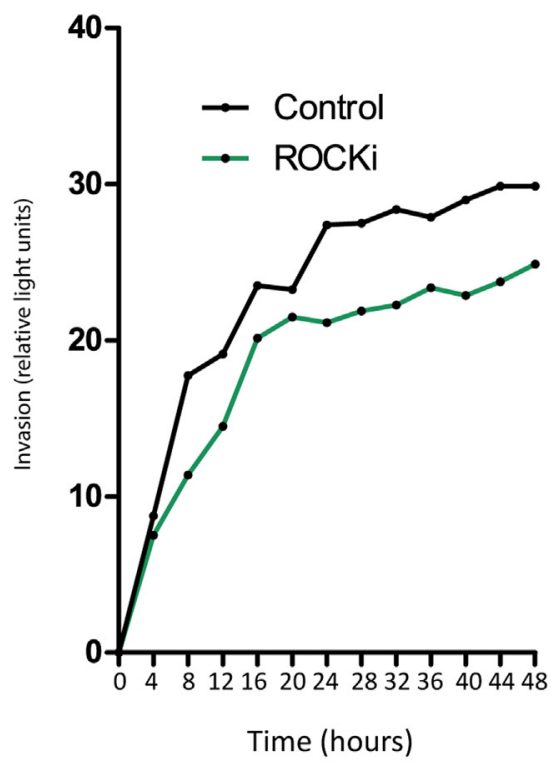

E

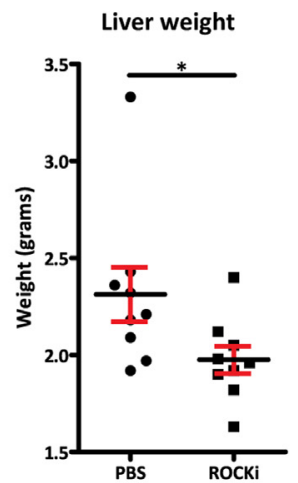

C

HT-29

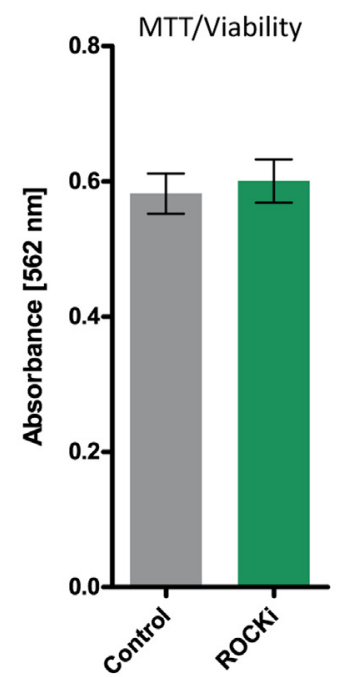

$\mathbf{F}$

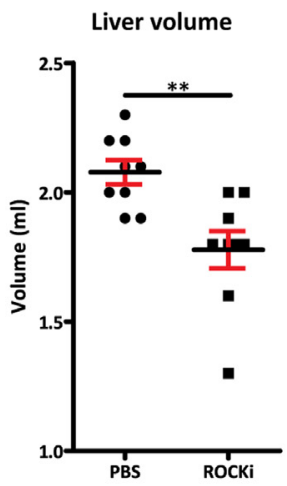


Supplementary Figure 5. (A) HT-29 cells were labeled with Celltracker and seeded in the upper chamber of a Transwell system. Cells that had migrated through Matrigel into the lower chamber were measured every 2 hours for 48 hours in total. During the invasion assay cells were treated with PBS or $100 \mathrm{ng} / \mathrm{mL}$ BMP-2. (B) HT-29 cells were labeled with Celltracker and seeded in the upper chamber of a Transwell system. Cells that had migrated through Matrigel into the lower chamber were measured every 2 hours for 48 hours in total. During the invasion assay cells were treated with PBS or $2.5 \mu \mathrm{mol} / \mathrm{L}$ of the ROCK inhibitor Y-27632 in PBS. (C) HT-29 cells were treated with $2.5 \mu \mathrm{mol} / \mathrm{L}$ of the ROCK inhibitor Y-27632 in PBS or PBS alone for 48 hours. Cell viability/proliferation was measured using a MTT assay. $(D)$ Correlation between the whole-mouse scans and the ex vivo liver scans. The association between the quantification of the 2 scans is a log regression, as follows: $y=$ $10^{*}\left(1.51^{\star} \log (x)-2.86\right)$. (E) Measurement of the weight of the livers. $(F)$ Measurement of the liver volume. (G) H\&E histology liver sections. Two examples without metastases from the PBS-treated group and 2 examples with metastases from the ROCK inhibitor group are shown. Student $t$ tests were performed $\left({ }^{\star}<.05,{ }^{\star \star}<.01,{ }^{\star \star \star}<.001\right)$. Data are presented as means \pm SEM. 
A

\begin{tabular}{|l|l|c|c|c|}
\hline \multicolumn{2}{|c|}{} & \multicolumn{3}{|l|}{ Distribution BMP components } \\
\cline { 3 - 5 } \multicolumn{2}{|c|}{} & $\begin{array}{l}\text { BMPReceptor } \\
\text { positive }\end{array}$ & $\begin{array}{l}\text { BMPReceptor } \\
\text { negative }\end{array}$ & Total \\
\hline \multirow{2}{*}{ SMAD4 } & Negative & $36(24.8 \%)$ & $23(15.9 \%)$ & $59(40.7 \%)$ \\
& Positive & $46(31.7 \%)$ & $40(27.6 \%)$ & $86(59.3 \%)$ \\
\cline { 2 - 5 } & Total & $82(56.6 \%)$ & $63(43.5 \%)$ & $145(100 \%)$ \\
\hline
\end{tabular}

B

\begin{tabular}{|c|c|c|c|c|}
\hline & \multicolumn{3}{|c|}{ Distribution TGF $\beta$ components } \\
\hline & & $\begin{array}{l}\text { TGFBReceptor } \\
\text { positive }\end{array}$ & $\begin{array}{l}\text { TGF } \beta \text { Receptor } \\
\text { negative }\end{array}$ & Total \\
\hline \multirow[t]{3}{*}{ SMAD4 } & Negative & $37(25.5 \%)$ & $22(15.2 \%)$ & $59(40.7 \%)$ \\
\hline & Positive & $56(38.6 \%)$ & $30(20.7 \%)$ & $86(59.3 \%)$ \\
\hline & Total & 94 (64.1\%) & $52(35.9 \%)$ & $72(100 \%)$ \\
\hline
\end{tabular}

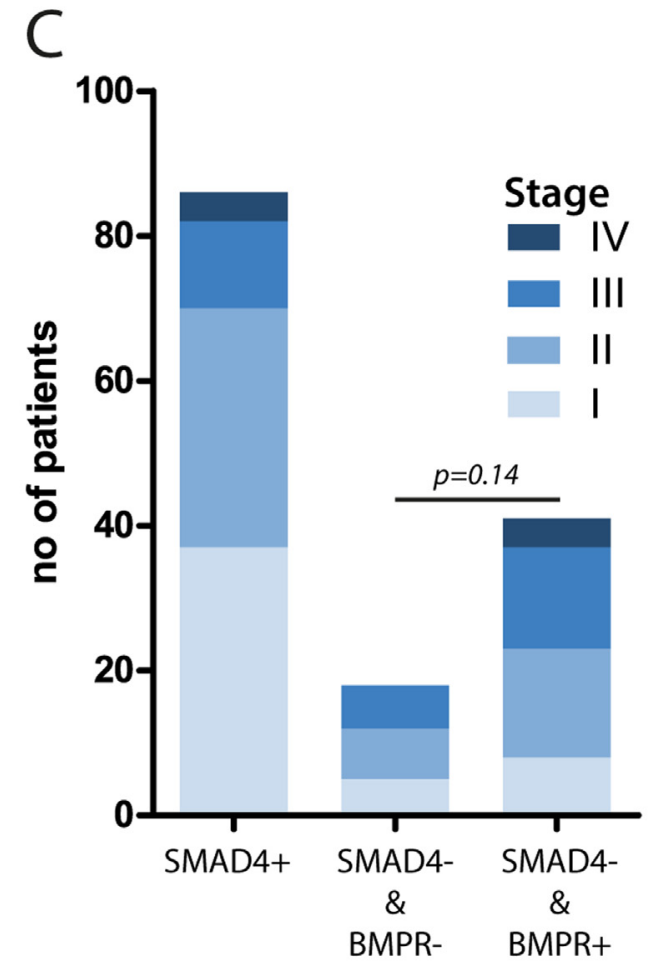

D

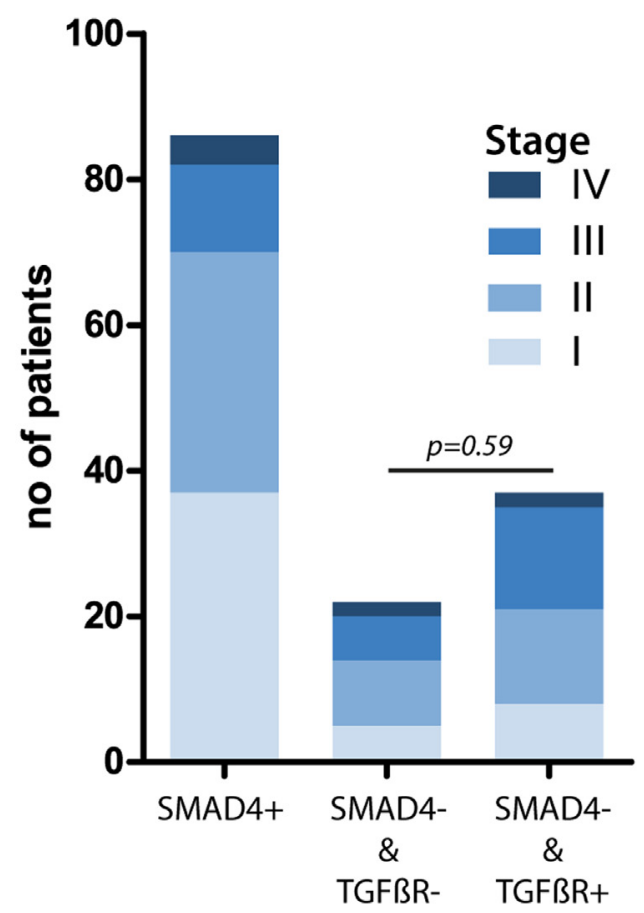

Supplementary Figure 6. (A) Colorectal cancer tissue of 145 patients was stained for SMAD4, BMPR1A, BMPR1B, and BMPR2 using immunohistochemistry. The table shows the distribution of the BMP signaling groups. The cancers were first divided in SMAD4 positive and SMAD4 negative. Then the groups were subdivided into BMPR-positive or BMPR-negative subgroups. (C) Analysis similar to panel $B$ only using TGF $\beta$-receptor expression instead of BMP-receptor expression. $(D)$ Distribution of the tumor stages within the groups based on SMAD4 and BMP-receptor expression. 
Supplementary Table 1.Kinase Inhibitors

\begin{tabular}{|c|c|c|c|c|}
\hline Substance & Function/inhibits & Concentration used & IC50 & Company \\
\hline hBMP-2 & BMP ligand (activates BMP) & $100 \mathrm{ng} / \mathrm{mL}$ & - & R\&D systems \\
\hline hNoggin & BMP & $500 \mathrm{ng} / \mathrm{mL}$ & - & R\&D systems \\
\hline LDN-193189 & BMPR1A & $5 \mathrm{nmol} / \mathrm{L}$ & $5 \mathrm{nmol} / \mathrm{L}$ & AxonMedchem \\
\hline Y-27632 & ROCK & $2.5 \mu \mathrm{mol} / \mathrm{L}$ & $2-10 \mu \mathrm{mol} / \mathrm{L}$ & Cayman/Millipore \\
\hline PD-098059 & MEK/ERK & $10 \mu \mathrm{mol} / \mathrm{L}$ & $10 \mu \mathrm{mol} / \mathrm{L}$ & Cayman/Sigma \\
\hline SP-600125 & JNK & $20 \mu \mathrm{mol} / \mathrm{L}$ & $5-20 \mu \mathrm{mol} / \mathrm{L}$ & Cayman/Sigma \\
\hline LY-294002 & Phosphoinositide 3-kinase & $10 \mu \mathrm{mol} / \mathrm{L}$ & $10 \mu \mathrm{mol} / \mathrm{L}$ & Cayman/Sigma \\
\hline $\mathrm{H}-7$ & Protein kinase $\mathrm{A}$ and Protein kinase $\mathrm{C}$ & $10 \mu \mathrm{mol} / \mathrm{L}$ & $10 \mu \mathrm{mol} / \mathrm{L}$ & Cayman \\
\hline SC-514 & $\mathrm{I}_{\kappa} \mathrm{B}$ kinase $2(\mathrm{IKK} 2)$ & $12 \mu \mathrm{mol} / \mathrm{L}$ & 3-12 $\mu \mathrm{mol} / \mathrm{L}$ & Cayman \\
\hline Tyrphostin AG 1295 & platelet-derived growth factor & $0.5 \mu \mathrm{mol} / \mathrm{L}$ & $0.5 \mu \mathrm{mol} / \mathrm{L}$ & Cayman \\
\hline Damnacanthal & $\begin{array}{l}\text { p56 lymphocyte-specific protein tyrosine } \\
\text { kinase }\end{array}$ & $620 \mathrm{nmol} / \mathrm{L}$ & $620 \mathrm{nmol} / \mathrm{L}$ & Cayman \\
\hline Piceatannol & Spleen tyrosine kinase & $10 \mu \mathrm{mol} / \mathrm{L}$ & $10 \mu \mathrm{mol} / \mathrm{L}$ & Cayman \\
\hline AG-490 & Janus kinase 2 & $10 \mu \mathrm{mol} / \mathrm{L}$ & $10 \mu \mathrm{mol} / \mathrm{L}$ & Cayman \\
\hline $\mathrm{KN}-93$ & Calmodulin-dependent protein kinase II & $370 \mathrm{nmol} / \mathrm{L}$ & $370 \mathrm{nmol} / \mathrm{L}$ & Cayman \\
\hline ML-7 & Myosin light chain kinase & $0.5 \mu \mathrm{mol} / \mathrm{L}$ & $0.5 \mu \mathrm{mol} / \mathrm{L}$ & Cayman \\
\hline N9-isopropyl-olomourcine & $\begin{array}{l}\text { Cyclin-dependent kinase 1/cyclin B en } \\
\text { CDK5/p35 }\end{array}$ & $3 \mu \mathrm{mol} / \mathrm{L}$ & 2 and $3 \mu \mathrm{mol} / \mathrm{L}$ & Cayman \\
\hline Roscovitine & CDK2/cyclin E & $0.1 \mu \mathrm{mol} / \mathrm{L}$ & $0.1 \mu \mathrm{mol} / \mathrm{L}$ & Cayman \\
\hline ZM 336372 & $\begin{array}{l}\text { murine leukemia viral oncogene } \\
\text { homolog } 1\end{array}$ & $70 \mathrm{nmol} / \mathrm{L}$ & $70 \mathrm{nmol} / \mathrm{L}$ & Cayman \\
\hline LFM-A13 & $\begin{array}{l}\text { Bruton's tyrosine kinase and Polo-like } \\
\text { kinase }\end{array}$ & $10 \mu \mathrm{mol} / \mathrm{L}$ & 2.5 and $10 \mu \mathrm{mol} / \mathrm{L}$ & Cayman \\
\hline Indirubin & $\begin{array}{l}\text { Cyclin-dependent kinases and GSK- } 3 \beta \\
\text { inhibitor }\end{array}$ & $75 \mathrm{nmol} / \mathrm{L}$ & $75 \mathrm{nmol} / \mathrm{L}$ and $0.19 \mu \mathrm{mol} / \mathrm{L}$ & Cayman \\
\hline Apigenin & Casein Kinase activity & $30 \mu \mathrm{mol} / \mathrm{L}$ & $30 \mu \mathrm{mol} / \mathrm{L}$ & Cayman \\
\hline Rapamycin & mammalian target of rapamyci & $0.1 \mathrm{nmol} / \mathrm{L}$ & $0.1 \mathrm{nmol} / \mathrm{L}$ & Cayman \\
\hline BML-257 & AKT1 & $100 \mathrm{nmol} / \mathrm{L}$ & 64 and $98 \mathrm{nmol} / \mathrm{L}$ & Cayman \\
\hline
\end{tabular}

NOTE. For the treatment of cancer cell line cells, the median inhibitory concentration for each specific kinase was used. IC50, median inhibitory concentration.

Supplementary Table 2. Primer Sequences

\begin{tabular}{lll}
\hline \multicolumn{1}{c}{ Gene } & \multicolumn{1}{c}{ Forward ('5-‘3) } & Reverse ('5-'3) \\
\hline hCDH-1 & Category no: PPH00135F & \\
hVimentin & CTGGATTCCTCTTCGTGGA & CGAAACACCCTGCAATCTT \\
hSNAl1 & CCTTCTCTAGGCCTGGCT & AGGTTGGAGCGGTCAGC \\
hZEBG1 & TGGTTGCTTCAAGGACACAT & GTGCAGTGAGGGCAAGAA \\
hGAPDH & AAGAATCACAGTGGAGAGAAGCCA & CGTTCTTGCAGTTTGGCATT \\
& GCACCGTCAAGGCTGAGAAC & ATGGTGGTGAAGACGCCAGT
\end{tabular}

NOTE. Primers were manufactured by Invitrogen (except for $\mathrm{CDH}-1$, which was purchased from Qiagen).

GAPDH, glyceraldehyde-3-phosphate dehydrogenase. 
Supplementary Table 3. List of Primary Antibodies for Immunoblotting

\begin{tabular}{|c|c|c|c|c|c|c|c|}
\hline Protein & Phospho site & Clone & Company & Product number & Source & Size, kD & Dilution \\
\hline E-cadherin & - & G-10 & Santa Cruz & sc-8226 & Mouse monoclonal & 120 & $1: 200$ \\
\hline Vimentin & - & $\mathrm{R} 28$ & Cell Signaling & 3932 & Rabbit polyclonal & 57.5 & $1: 500$ \\
\hline ACTIN & - & $\mathrm{I}-19$ & Santa Cruz & sc-1616 & Rabbit polyclonal & 43 & $1: 10,000$ \\
\hline $\mathrm{p}-\mathrm{AKT}$ & Thr308 & - & Cell Signaling & 9275 & Rabbit polyclonal & 60 & $1: 500$ \\
\hline p-p38 MAPK & Thr180/Tyr182 & 3D7 & Cell Signaling & 9215 & Rabbit polyclonal & 43 & $1: 500$ \\
\hline $\mathrm{p}-\mathrm{MKK} / 6$ & Ser189/Ser207 & - & Cell Signaling & 9231 & Rabbit polyclonal & $40 / 41$ & $1: 500$ \\
\hline p-JNK & Thr183/Tyr185 & - & Cell Signaling & 9251 & Rabbit polyclonal & $46 / 54$ & $1: 500$ \\
\hline $\mathrm{p}$-ERK1/2 & Thr202/Tyr204 & 20G11 & Cell Signaling & 4376 & Rabbit monoclonal & $42 / 44$ & $1: 500$ \\
\hline $\mathrm{p}-\mathrm{GSK} \alpha / \beta$ & Ser21/9 & - & Cell Signaling & 9331 & Rabbit polyclonal & $46 / 51$ & $1: 500$ \\
\hline SIP1 & - & - & Sigma-Aldrich & SAB1406675 & Mouse polyclonal & 31.6 & $1: 500$ \\
\hline p-Cofilin & Ser3 & $77 \mathrm{G} 2$ & Cell Signaling & 3313 & Rabbit monoclonal & 19 & $1: 500$ \\
\hline p-LIMK1/2 & Thr508/Thr505 & - & Cell Signaling & 3841 & Rabbit polyclonal & 72 & $1: 500$ \\
\hline BMPR1A & - & $\mathrm{H}-60$ & Santa Cruz & sc-20736 & Rabbit polyclonal & 66 & $1: 200$ \\
\hline BMPR1B & - & $\mathrm{H}-44$ & Santa Cruz & sc-25455 & Rabbit polyclonal & 50 & $1: 200$ \\
\hline BMPR2 & - & G-25 & Santa Cruz & sc- 130704 & Rabbit polyclonal & 115 & $1: 200$ \\
\hline SMAD4 & - & B-8 & Santa Cruz & sc-7966 & Mouse monoclonal & 61 & $1: 500$ \\
\hline
\end{tabular}

NOTE. All secondary horseradish-peroxidase-conjugated antibodies were obtained from Dako (Glostrup, Denmark).

Supplementary Table 4. Patient Characteristics

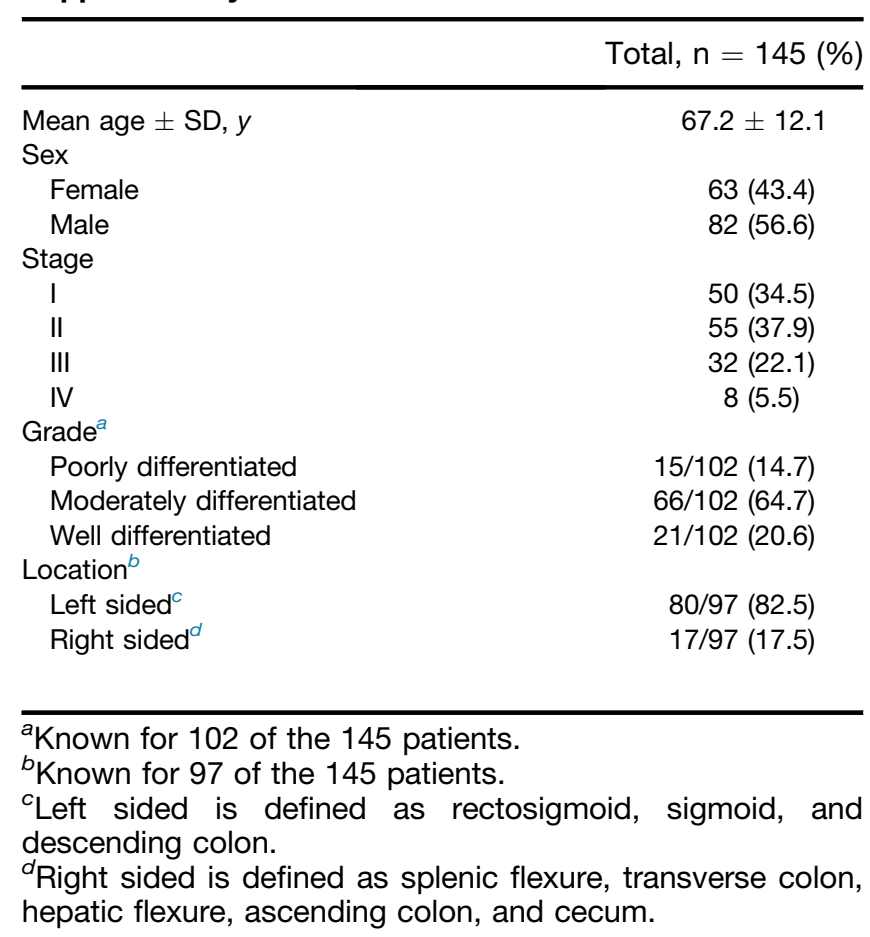


Supplementary Table 5. List of Primary Antibodies for Immunohistochemistry

\begin{tabular}{|c|c|c|c|c|c|c|c|}
\hline Protein & Company & Category number & Source & Antigen retrieval & Blocking & Incubation & Dilution \\
\hline BMPR1A & $R \& D$ Systems & MAB24061 & Mouse monoclonal & Tris/EDTA & Goat serum & 1 hour at RT & $1: 100$ \\
\hline BMPR1B & R\&D Systems & MAB5051 & Mouse monoclonal & Tris/EDTA & Goat serum & 1 hour at RT & $1: 100$ \\
\hline BMPR2 & $R \& D$ Systems & AF811 & Goat polyclonal & Citrate & TENG-T & Overnight at $4^{\circ} \mathrm{C}$ & $1: 100$ \\
\hline TGF $\beta \mathrm{R} 1$ & Santa Cruz & $\mathrm{H}-100$ & Rabbit polyclonal & Tris/EDTA & Goat serum & 1 hour at RT & $1: 100$ \\
\hline TGF $\beta$ R2 & Santa Cruz & $\mathrm{L}-21$ & Rabbit polyclonal & Citrate & TENG-T & Overnight at $4^{\circ} \mathrm{C}$ & $1: 100$ \\
\hline SMAD4 & Santa Cruz & B-8 & Mouse monoclonal & Citrate & TENG-T & Overnight at $4^{\circ} \mathrm{C}$ & $1: 100$ \\
\hline
\end{tabular}

RT, room temperature; TENG-T, $10 \mathrm{mmol} / \mathrm{L}$ Tris, $5 \mathrm{mmol} / \mathrm{L}$ EDTA, $0.15 \mathrm{~mol} / \mathrm{L} \mathrm{NaCl}, 0.25 \%$ gelatin, and $0.05 \%$ Tween 20 , $\mathrm{pH}$ 8.0.

Supplementary Table 6. Scoring System for BMP/TGF $\beta$ Receptor Immunohistochemistry

\begin{tabular}{lccc}
\hline & \multicolumn{3}{c}{ Percentage of cells stained } \\
\cline { 2 - 4 } Intensity of staining & $<10 \%$ & $10 \%-30 \%$ & $>30 \%$ \\
\hline No & 0 & 0 & 0 \\
Weak & 0 & 0 & 1 \\
Moderate & 0 & 1 & 2 \\
Strong & 0 & 2 & 4
\end{tabular}

NOTE. A BMP/TGF $\beta$-receptor expression score of 0 or 1 is considered negative. A score of 2 or 3 is considered positive. 